Trabajo seleccionado para su publicación por el jurado del Premio Estudios Financieros, formado por: don Antonio Bautista García-Vera; don Luis Alberto Guijarro Rojo; doña Ana Hidalgo Tena; doña Blanca Lozano Cutanda y don José Eugenio Martínez Falero.

\title{
Optimización de la evaluación integral del alumnado: la ofimática al rescate
}

\section{Extracto:}

La evaluación del alumnado se centra principalmente en asignar calificaciones en las diferentes asignaturas con las plataformas educativas que permiten introducir notas numéricas. En algunas se pueden incluir datos de absentismo del alumnado, pero sigue sin haber métodos que permitan una valoración integral tanto de la clase como del alumno. Desarrollar una herramienta que supla esas limitaciones o las complemente se convierte en el objetivo principal de este trabajo. La ofimática pone al servicio de cualquier usuario inmensas posibilidades para obtener una evaluación integral del alumno.

Una plantilla de muestra interactiva desarrollada a partir de la ofimática permite dotar al maestro de un instrumento para evaluar cualquier asignatura o clase en parámetros estadísticos. La plantilla se muestra más eficaz que las plataformas educativas actuales en los criterios de mostrar parámetros estadísticos de la clase y de los alumnos, así como a la hora de generar informes individualizados.

Palabras claves: evaluación, evaluación relativa, evaluación integral, plataforma educativa ofimática, estadística, curva de Gauss. \footnotetext{
${ }^{1}$ A. Pastor García, maestro de Educación Primaria, licenciado en Psicología y alumno del Máster en Dirección y Gestión de Recursos Humanos
impartido por el CEF.
} 


\section{Optimization to comprehensive evaluation of students: Office to the rescue}

\section{Abstract:}

Student assessment focuses primarily on assigning grades in different subjects with educational platforms to introduce numerical grades. Some allow you to enter data absenteeism of students but still no methods that allow a comprehensive assessment of both the class and the student. Developing a tool that mitigates these limitations or supplement becomes the main objective of this work. Office automation makes available to any user immense possibilities for a comprehensive assessment of the student.

A template developed interactive displays from the office can provide a tool to evaluate any subject or class statistical parameters. The template is more effective than current educational platforms criteria show statistical parameters of the class and students as well as to generate individualized reports.

Keywords: evaluation, relative evaluation, comprehensive assessment, educational platform, office, statistics, curve Gauss.

\section{La plataforma donde}

\section{habitualmente introducimos}

las notas tan solo representa la

valoración del alumno con una

calificación, pero no un diagrama general de la clase

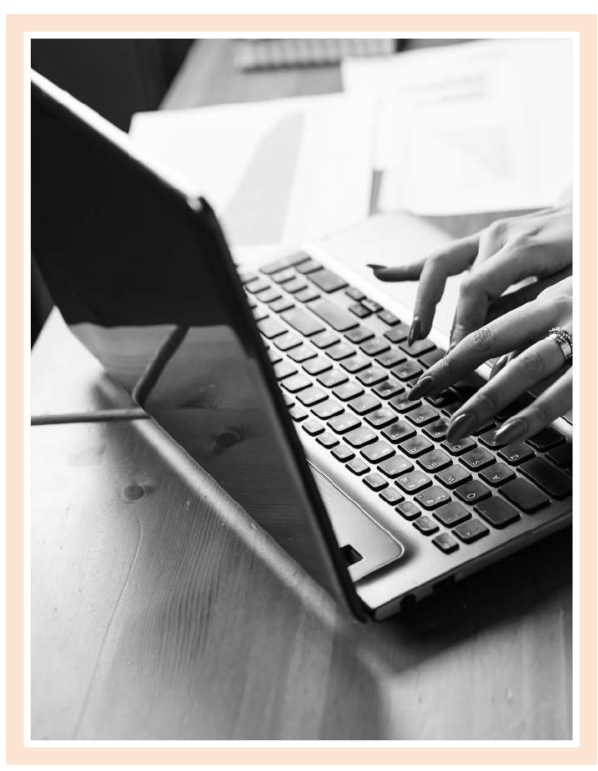

\section{INTRODUCCIÓN DEL TRABAJO}

La ofimática es el conjunto de herramientas o aplicaciones informáticas que se utilizan en funciones de oficina para permitir la optimización, automatización e implementación de las tareas relacionadas. El conjunto de programas afines puede realizar funciones tan diversas como procesar textos, crear bases de datos o presentaciones. Principalmente, los programas Excel y Access han sido utilizados para este trabajo, englobados dentro del paquete ofimático comercial Windows Office de Microsoft (MS Offi$\mathrm{ce})$, ya que presenta como principal ventaja, frente a otros paquetes ofimáticos (Open Office, Corel WordPerfect, Office Suite, IBM, Lotus Smarsuite, Ability Office, EasyOffice, StarOffice, AppleWorks, iWork y NeoOffice, estos últimos para Mac), que es el que predomina en el mercado; de hecho está considerado casi como un estándar y posee sus propios formatos cerrados de documentos para cada uno de sus programas, dejando una pobre compatibilidad entre las suites de Microsoft con otros formatos libres o comerciales. 
El OpenOffice es un paquete ofimático de código abierto (por lo tanto, libre), con menos recursos que el Microsoft Office, que posee limitaciones técnicas, como el funcionamiento y la edición de macros. Los programas Excel y Access descritos antes permiten recopilar datos sobre las calificaciones de los alumnos, tales como número de excelentes, proporción de notas, porcentajes de mejora o de progreso respecto al resto de la clase. La plantilla creada refleja todas estas ventajas. Se puede ir modificando y perfeccionando con el tiempo a medida de las necesidades del maestro, ya que la programación didáctica es algo vivo. Por ejemplo, podría realizarse un gráfico que midiera la evolución de un alumno en particular.

La plataforma donde habitualmente introducimos las notas tan solo representa la valoración del alumno con una calificación, pero no un diagrama general de la clase, ya que únicamente se pueden observar las notas de los alumnos pero no tendencias o medias para comparar las asignaturas entre sí, etc.

La figura 1 corresponde al programa Amic Professor, que se utiliza en algunas escuelas de Cataluña, con

\section{Los programas comerciales que permiten introducir notas posibilitan observar las valoraciones de los alumnos, pero no una referencia estadística de su mejoría 0 , estadísticamente, la distribución de notas o de ausencias en clase}

algunos datos y nombres ficticios introducidos. El programa permite tan solo introducir la evaluación de la asignatura en función de códigos numéricos que asignan una valoración en forma de frase, como, por ejemplo: «Necesita mejorar su vocabulario». No permite observar datos globales de la clase. Otras plataformas como «Alexia» permiten introducir incidencias y altas de alumnos, informes o ausencias, pero siguen sin dar datos para controlar mejor la evaluación integral de la clase 0 del centro.

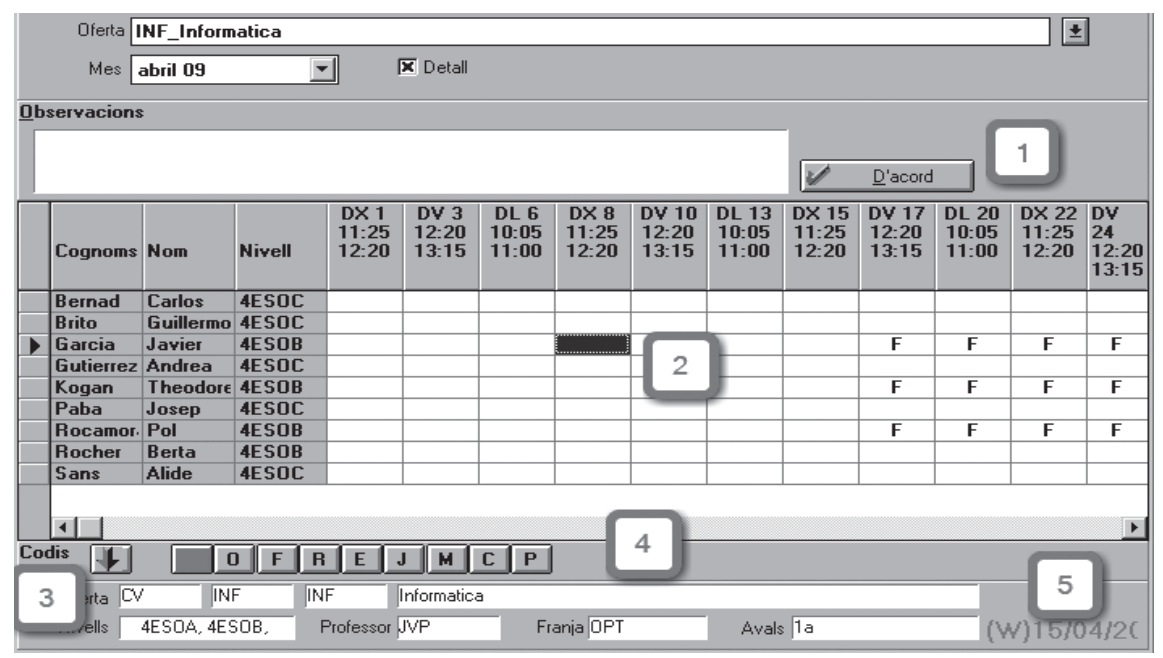


La capacidad de Excel para crear bases de datos y manejarlas según valores introducidos representa un ahorro de tiempo a la hora de introducir las notas promedio de las asignaturas, dada su habilidad para dejar programadas las funciones.

La plantilla Excel/Access requiere un cierto conocimiento para su utilización y tiempo para programar las variables, pero una vez realizada permite una visión óptima de la clase para ver si ha habido mejora en algunos aspectos o no.

Los programas comerciales que permiten introducir notas posibilitan observar las valoraciones de los alumnos, pero no una referencia estadística de su mejoría o, estadísticamente, la distribución de notas o de ausencias en clase.

Estas plantillas permiten una transmisión de información más rápida de la clase y de los datos de los alumnos.

El programa Access permite crear datos en forma de ficheros individualizados, dando muestras de cada alumno de forma individual, y enlazar directamente

\section{La capacidad de Excel para crear bases de datos y manejarlas según valores introducidos representa un ahorro de tiempo a la hora de introducir las notas promedio de las asignaturas, dada su habilidad para dejar programadas las funciones}

con un fichero Excel, cuyos cambios se reproducirán inmediatamente en el fichero Access asociado.

Un ejemplo de plantilla realizada con Excel (véase figura 2), en el que se recogen las medidas de algunos alumnos en las asignaturas y su media de trimestre, de curso, y la distribución de notas, da una idea de las ventajas que puede ofrecer la ofimática aplicada a la evaluación integral del alumno.

Figura 2. Muestra 1. Notas trimestrales y calificaciones

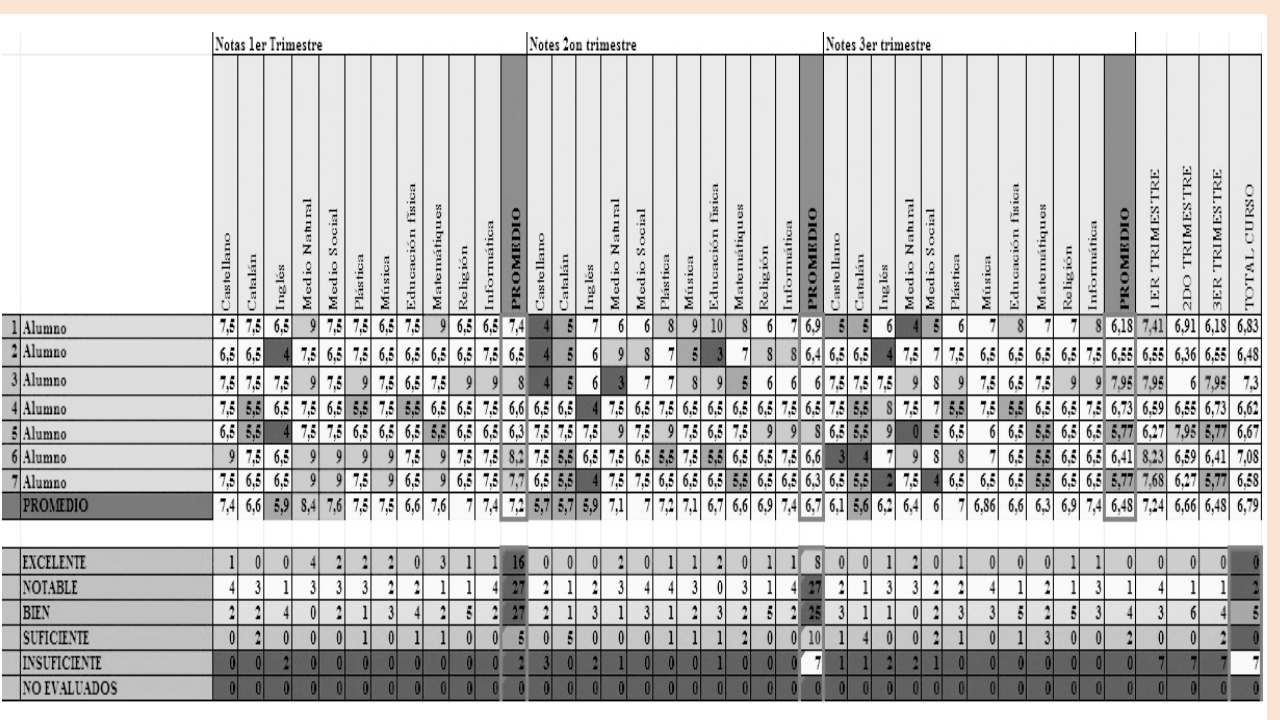

Fuente: elaboración propia. 


\section{JUSTIFICACIÓN}

Este tema de investigación pretende mostrar la aplicación de programas del paquete MS Office (Excel y Access) a las medidas de evaluación de un aula, las posibilidades que ofrece para valorar y obtener datos de una clase y/o de un colegio cualquiera, de forma que se tendrá que buscar algún otro sistema para representar la evaluación de los alumnos al margen del tradicional cuaderno escolar. También hace hincapié en que es contradictorio que haya maestros que estén exigiendo un nivel de informática a alumnos de primaria que ellos mismos no poseen. El trabajo pretende presentar las ventajas que obtendrían si se actualizaran formativamente con medios tecnológicos básicos como es la ofimática, que hoy en día cada maestro debería tener presente y utilizar.

Existen trabajos sobre la formación de los maestros en relación a las tecnologías de la información y la comunicación (TIC) que revelan que la finalidad de los cursos de formación es ayudar a los estudiantes a adquirir competencias y no integrarlos curricularmente favoreciendo el proceso enseñanza/aprendizaje.

Dichos estudios obtuvieron una serie de conclusiones sobre la formación de los maestros en relación con las TIC. En un $66 \%$ de los cursos realizados, el propósito que se planteaba era que los maestros aprendieran herramientas básicas para ayudar a los estudiantes a adquirir las competencias de su uso, pero en menor medida se planteaban utilizar los recursos aprendidos con el propósito de integrarlos curricularmente como apoyo al proceso de enseñanza/aprendizaje.

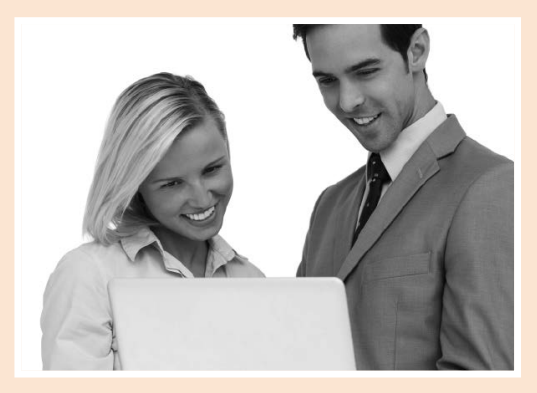

\section{Existen trabajos sobre la formación de los maestros en relación a las TIC que revelan que la finalidad de los cursos de formación es ayudar a los estudiantes a adquirir competencias y no integrarlos curricularmente favoreciendo el proceso enseñanza/aprendizaje}

Otro estudio más reciente concluyó que ni los docentes sabían sacar partido pedagógico a los ordenadores ni los alumnos los utilizaban para otra cosa que fuese buscar información. Los autores del estudio mostraron que los propios docentes reconocían lagunas importantes en sus competencias para utilizar estas tecnologías como instrumentos didácticos tanto para el aprendizaje como para sí mismos.

Solo un tercio de los profesores consideraba que las TIC ayudaban a mejorar los resultados de los alumnos y, por tanto, no podían entregarse a algo en lo que no acababan de creer. Se mostró también cómo una tercera parte de los profesores de secundaria no sabían utilizar el ordenador, y hablamos de un ramo donde la implantación del ordenador en el aula es habitual, donde se dan los proyectos $1 \times 1$, como en Cataluña, con un ordenador para cada alumno, y donde la formación del profesorado es más extensa y técnica.

En este trabajo se compara la utilidad de distintas herramientas de evaluación y se muestran las posibilidades que ofrecen algunos programas informáticos convencionales. La comparación incluirá algunas de las plataformas más representativas de muestra (como, por ejemplo, Amic Professor, Alexia, etc.) y se demostrarán las ventajas que puede aportar la plantilla en el aspecto de evaluación del alumnado. Actualmente, las plataformas de los centros docentes no dan suficientes soluciones a los procesos de evaluación integral tanto de la clase como del propio estudiante y se centran en mejorar otros aspectos como el del absentismo. Mediante la creación de una herramienta con Access/Excel se dará soporte técnico a este cambio en la manera de evaluar y su aplicación práctica con algunos datos de ejemplo. 


\section{UTILIDAD}

La utilidad de la investigación pretende dejar de forma práctica unas plantillas como muestra que permitan el control de datos de cada clase en el colegio. Las plantillas pueden abarcar datos de una clase en concreto y obtener una referencia de una asignatura específica y medias de todo el centro con aplicaciones múltiples y variadas.

Hoy día los maestros se muestran un poco desconfiados respecto a las TIC y sus utilizaciones pedagógicas, pero trabajos como este pretenden mostrar la utilidad y el ahorro de tiempo que darían estas herramientas. Esta plantilla permite tener en todo momento a nuestra disposición los datos de cada alumno y del grupo/clase, permitiendo una visión mucho más amplia de la clase y de las mejoras de los alumnos. La evaluación relativa del alumno respecto a su grupo/ clase no implica modificar su evaluación «absoluta», pero sí una visión complementaria, para obtener así una evaluación integral, compuesta de la evaluación tradicional más la evaluación relativa.

Desde el punto de vista teórico, el trabajo propuesto puede proporcionar un enfoque adicional y abrir un debate con respecto al modelo complementario de evaluación del estudiante y el grupo, pudiendo generar nuevas perspectivas sobre los procedimientos que actualmente se están utilizando. La conveniencia de estos métodos y la detección de sus deficiencias están abiertas siempre a debate y, continuamente, se desarrollan nuevas plataformas educativas de introducción de notas para superar sus defectos.

\section{La evaluación relativa del alumno respecto a su grupo/clase no implica modificar su evaluación "absoluta», pero sí una visión complementaria, para obtener así una evaluación integral, compuesta de la evaluación tradicional más la evaluación relativa}

\section{OBJETIVOS}

- Objetivo principal:

- Desarrollar un método ofimático para gestionar la evaluación integral del alumno en clase de primaria.

- Objetivos secundarios:

- Definir conceptualmente «evaluación integral» del alumno de primaria.

- Comparar los métodos o herramientas ofimáticas disponibles que gestionan la evaluación del alumno de primaria.

- Diseñar una herramienta ofimática propia mediante los programas Access/Excel para la evaluación integral del alumno que mejore y complemente las herramientas actuales.

\section{METODOLOGÍA}

\subsection{Criterios para definir «evaluación in- tegral»}

Algunos autores han propuesto diversos conceptos sobre la manera de definir «evaluación integral». Casanova es la autora que más hincapié hace en la necesidad del correcto proceso de evaluación y se muestra crítica con algunos de los planteamientos más aceptados. De acuerdo con Casanova (1992), según su Manual de evaluación educativa, la evaluación educativa se define como la que se centra principalmente en los procesos de enseñanza y aprendizaje, valorando tanto lo memorizado como la formación como persona en función de actitudes, valores y normas. En su libro muestra cómo los procesos de enseñanza y aprendizaje muchas veces no tienen los procesos evaluativos necesarios para ser evaluados correctamente.

Por su parte, Álvarez González (1995) establece la necesidad de mecanismos de evaluación tanto para el aprendizaje como para otros procesos afines, como el de orientación profesional. Otro autor como Castillo (2003) comienza a relacionar la evaluación educativa con la evaluación de procesos de calidad, determinando la evaluación como un sistema no solo calificativo, sino también de mejora continua. 


\section{(...) el trabajo propuesto puede proporcionar un enfoque adicional y abrir un debate con respecto al modelo complementario de evaluación del estudiante y el grupo, pudiendo generar nuevas perspectivas sobre los procedimientos que actualmente se están utilizando. La conveniencia de estos métodos y la detección de sus deficiencias están abiertas siempre a debate y, continuamente, se desarrollan nuevas plataformas educativas de introducción de notas para superar sus defectos}

\subsection{Criterios comparativos}

Es necesario definir previamente una serie de parámetros para comparar las ventajas de la plantilla frente a las plataformas presentadas más representativas actualmente en el sistema educativo.

A) Alumno

- Introducción de notas. Continua o en determinados periodos.

- Calificación. Numérica o categórica.

- Media individual. Posibilidad de media calificativa del alumno.

- Desviación estándar. Desviación individual del alumno respecto del grupo/clase.

Se escogen estos parámetros siguiendo la tradición evaluativa de notas absolutas del alumno, introduciendo nuevas medidas, como la media o la desviación estándar respecto al grupo/clase que la mayoría de plataformas no permiten observar.

\section{B) Clase}

- Alumno respecto al grupo/clase. Desviación estándar respecto al grupo y nota calificativa al respecto.

A pesar de no estar inmerso en el mundo educativo, sino empresarial, Fleitman (2008) cita la evaluación integral como una necesidad de las empresas para obtener resultados lo más fiables y completos posibles. Estos conceptos para la consecución de resultados fiables también pueden ser aplicados a los colegios, obteniendo así datos muchos más completos no solo para el alumno, que se marcha con su boletín de notas a casa, sino también para los maestros, para el proceso de evaluación interna.

Finalmente, Airasian (2002), en su libro de La evaluación en el salón de clases, define la evaluación como el proceso de obtener, sintetizar e interpretar información para facilitar la toma de decisiones. Airasian es un autor que pone gran énfasis en la necesidad de sintetizar e interpretar información de manera que una evaluación más completa no se confunda con muchos más datos, pero sí que abarque más variables.

Estos autores son los que se han elegido principalmente como fuentes de referencia debido a su crítica constructiva hacia los principales métodos de evaluación y su preocupación por optimizar resultados.

- Media grupal. Media de la clase en las distintas asignaturas.

- Distribución porcentual. Distribución porcentual de la clase en segmentos según sus calificaciones.

Escoger estos parámetros implica utilizar medidas que la mayoría de plataformas no contemplan para poder observar mejor el progreso de la clase y del alumno.

\section{C) Asistencia}

- Asistencia diaria. Control de asistencia diaria.

- Asistencia total. Número total de ausencias por trimestre y curso.

Estos parámetros de asistencia habitualmente están en la secretaria del colegio, pero son de interés para el maestro al observar el comportamiento disciplinar del alumno y ver cuándo se acerca al porcentaje límite de no asistencia al colegio, lo que obliga a informar a servicios sociales de desatención al menor. 
D) Informe del alumno

- Informe. Informes individualizados del alumno.

- Progreso. Cuantificación del progreso del alumnado.

La elección de estos parámetros es la de tener un informe personal de cada alumno que permita al maestro disponer de información tanto para el análisis personal como para tratar con más detalle la evolución del alumno en las entrevistas con los padres.

\section{E) Sistema}

- Precio. Precio económico de la aplicación o plataforma.

- Formación. Necesidad de conocimiento previo de informática.

- Cuestiones técnicas. Espacio en disco, requerimientos (CPU, RAM, etc.) y conectividad.

- Privacidad y compatibilidad. Seguridad y compatibilidad de formatos.

Estos parámetros son propios de cualquier sistema informático para comparar las ventajas o el coste para la escuela en su implantación. Las cuestiones técnicas son importantes para que el maestro pueda trabajar con dicha plataforma no solo en los ordenadores del colegio, sino también desde su propia casa.

\section{La plantilla ofimática permite valorar a los alumnos según su relación con el grupo/ clase y obtener valores que permitan ver cómo se distribuye el grupo}

\section{Figura 3. Curva de Gauss. Distribución de muestra ordinaria}

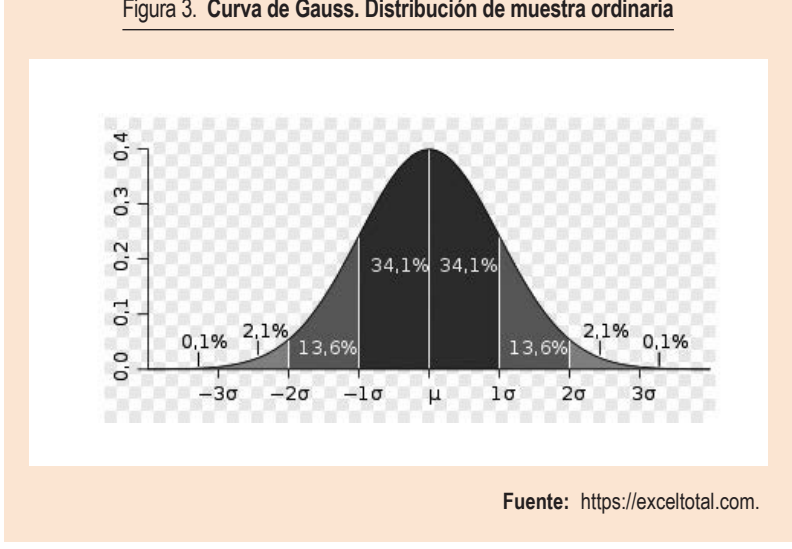

\subsection{Fundamentos estadísticos «evaluación relativizada»}

La plantilla ofimática que se presenta muestra la evaluación ordinaria junto con la evaluación a partir de la curva de Gauss (véase figura 3). La curva de Gauss representa la distribución normal de una muestra y cómo los sujetos se reparten según su valor dentro de esa muestra en relación a cuánto se desvían por encima o por debajo de la media del grupo. Los valores extremos representan lo extraordinario dentro de una muestra.

La evaluación relativizada se centra en la distribución normal de una curva de Gauss. La distribución normal de una muestra presenta a los sujetos respecto a una media central y la medida en que se alejan se define como la desviación estándar. La distribución ordinaria presenta a la mayoría del grupo (un $68,2 \%$ ) en torno a la media de la clase, a algunos que destacan por encima o por debajo del grupo (un 27,2\%), a otros que presentan resultados extraordinariamente alejados tanto por encima o por debajo del grupo (un $4,2 \%$ ), así como resultados extremos $(0,2 \%)$.

Todos estos factores y conceptos fueron desarrollados por Carl Friedrich Gauss en su estancia en Gotinga entre los años 1975 y 1978. Entre los muchos trabajos que desarrolló en torno a la teoría de números y al álgebra están los relacionados con la distribución normal de un grupo, cuyo modelo hoy día lleva el nombre en su honor. Los fundamentos de la distribución normal que realizó entonces siguen siendo la referencia a la hora de valorar la «normalidad» o lo «extraordinario» del comportamiento de sujetos en una muestra, tal como establecía Canavos (1992).

La plantilla ofimática permite valorar a los alumnos según su relación con el grupo/clase y obtener valores que permitan ver cómo se distribuye el grupo. Las notas que el alumno obtiene se puntúan según se aleja de la media del grupo teniendo en cuenta los valores habituales de dispersión de una curva de Gauss presentados anteriormente. 
Podría haber asignaturas en las que una gran mayoría de los alumnos no adquieren los conocimientos mínimos, pero con la evaluación relativizada podrían salir "aprobados», de forma que esta evaluación es tan solo un complemento para observar de qué modo progresa el alumno respecto al grupo/clase.

\section{MARCO TEÓRICO}

En la actualidad solo se tiene en consideración un modo de evaluar y algunas veces ese sistema se encuentra un poco limitado en la información que otorga sobre el alumno.

Las plataformas presentadas tienen en común que ofrecen una evaluación individualizada del alumnado, pero no permiten visualizar la clase en su conjunto $y$, algunas de ellas, presentan una considerable inversión de tiempo para introducir todos sus datos al requerir introducir unos códigos de notas en lugar de texto libre.

Para comprender mejor la evolución de la forma de evaluar a lo largo de la historia se aporta un breve resumen sobre su desarrollo.

\subsection{Marco histórico de la evaluación}

El concepto de «evaluación» ha variado mucho durante la historia, no solo en el campo de la educación. En la Edad Media se introducen los exámenes orales públicos en presencia de un tribunal, aunque al estar la educación limitada a la clase más adinerada, estos serían un mero trámite. En el Renacimiento, el interés por el hombre comienza a demandar la utilización de procedimientos selectivos que se instauran en el siglo XVIII a medida que aumenta la demanda de educación y la posibilidad de acceso. A más alumnado, mayor cantidad de normas que establecer sobre exámenes escritos y similares.

En el siglo XIX se establecen los sistemas habituales de educación con la obtención de grados que acrediten el conocimiento obtenido y surgen los exámenes para demostrar una pre-

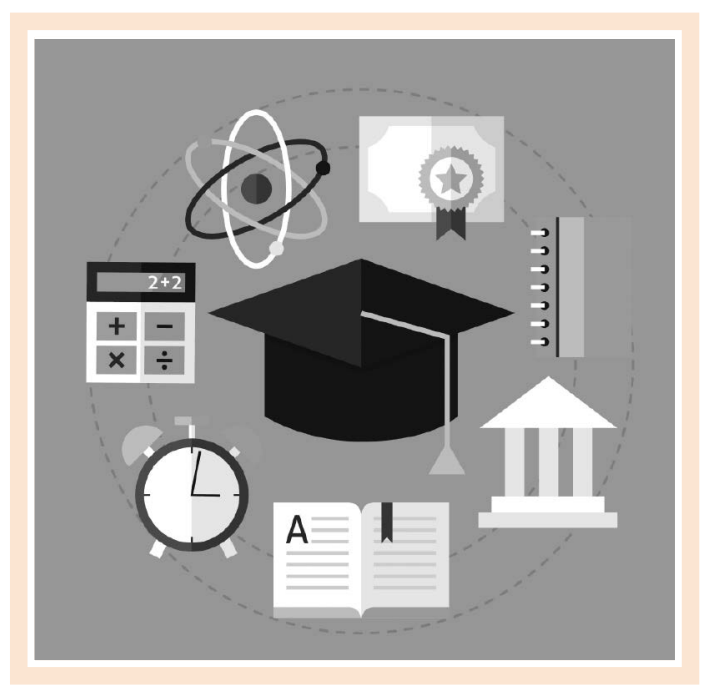

paración específica compatible con una mayor diversidad de trabajos. En 1845, Horace Mann comienza a utilizar los test escritos como medida, que se extienden a otras escuelas. J. M. Rice, a finales de 1897, publica un trabajo sobre la medición y evaluación, comparando la instrucción en diversas escuelas americanas. Dicho trabajo coincidió con un gran interés por la medición científica de las conductas humanas, y la evaluación recibe el condicionamiento de diversos factores, como múltiples corrientes filosóficas positivas y empíricas que se apoyan en la observación y en la experimentación como fuente del conocimiento verdadero, las teorías evolucionistas de Darwin y el desarrollo de métodos estadísticos y de la sociedad industrial, que potencia obtener unos mecanismos de acreditación para mostrar conocimientos.

El administrar pruebas de competencias o testing se desarrolló a principios del siglo XX, centrado en detectar diferencias individuales, hallando características y rendimiento de sujetos. Thorndike fue el autor de mayor influencia en este campo, junto con los trabajos en psicometría de Stanford Binet, aprovechados para las necesidades de reclutamiento en la Primera Guerra Mundial.

Al término de la contienda, los test derivan hacia el servicio social para medir tanto destrezas escolares en la educación como enfermedades o alteraciones mentales en la sanidad. Multitud de profesores desarrollan pruebas estandarizadas. 


\section{La evaluación diagnóstica es muy abstracta y no permite al maestro comprobar el grado en que el alumno ha asimilado las competencias básicas e implementar las medidas de seguimiento $y$ mejora necesarias}

La revolución promovida por Ralph W. Tyler en los años veinte condujo a las primeras discrepancias entre lo que se medía y pretendía enseñar. Tyler fue el primero en ofrecer una visión metódica, superando el conductismo y exponiendo la idea de currículum como compendio de objetivos que se querían conseguir, actividades para lograrlo y qué actitudes había que observar para demostrarlo y evaluarlo.

El concepto de «currículum» que ha llegado hasta nuestros días es substituido en nuestro país, a través de la Ley orgánica de la educación (LOE), de 2006, por el de «desarrollo de las competencias básicas». En el contexto actual se evalúa la adquisición del alumno de esas competencias básicas mediante la realización de exámenes en los que demuestre su conocimiento sobre la materia. La evaluación ordinaria presenta un importante matiz, ya que a las calificaciones obtenidas del alumno se le añaden algunas acotaciones, como el comportamiento o el esfuerzo, que sirven para ajustar en mayor o menor medida su nota, lo que significa un valor añadido a la información, que busca una evaluación más precisa del alumno, como establece Casanova (2004).

En la búsqueda de un modo más concreto de evaluar al estudiante, nos centramos en la conceptualización de la evaluación integral, analizando el panorama actual en cuanto a los estándares numéricos 0 categóricos utilizados habitualmente y se revisa el concepto de «evaluación relativa».

\subsection{Panorama actual (evaluación numérica o diagnóstica)}

Durante muchos años se ha utilizado en educación primaria la evaluación diagnóstica por la que todos los alumnos eran evaluados con dos ítems:

- Progresa adecuadamente (PA).

- Necesita mejorar (NM).

Algo insuficiente, según el autor Álvarez Méndez (2001), que determina la necesidad de evaluar para conocer lo aprendido y no solo calificar. Dos alumnos con niveles educativos y esfuerzos muy diferentes eran evaluados con la misma nota, de forma que muchos estudiantes dejaban de esforzarse y se preocupaban tan solo en trabajar lo mínimo.

La evaluación diagnóstica con los criterios de PA y NM apareció en 1981 con la aplicación de la Ley orgánica por la que se regula el estatuto de centros escolares (LOECE), propugnando la evaluación continua para el ciclo inicial y medio y ampliada al ciclo superior con la implantación de la Ley orgánica general del sistema educativo (LOGSE) en 1990. La LOE de 2006 empezó a gestionar el cambio hacia la nota numérica.

En la educación secundaria se imponía la evaluación numérica para que el alumno fuese adquiriendo una nota que sería crucial a la hora de hacer media con su nota de Selectividad en las Pruebas de Acceso a la Universidad (PAU). Entonces, se ha dado el caso de alumnos que estaban acostumbrados a que no se premiara su esfuerzo continuo en primaria y se han encontrado de repente con una evaluación que ha marcado su futuro. De ahí que desde hace unos pocos años se haya decidido implantar en la educación primaria la evaluación conceptual, basada en datos numéricos, y en la educación secundaria obligatoria (ESO), un modelo mixto que combine la evaluación conceptual con una nota numérica. En el bachillerato, la evaluación es puramente numérica.

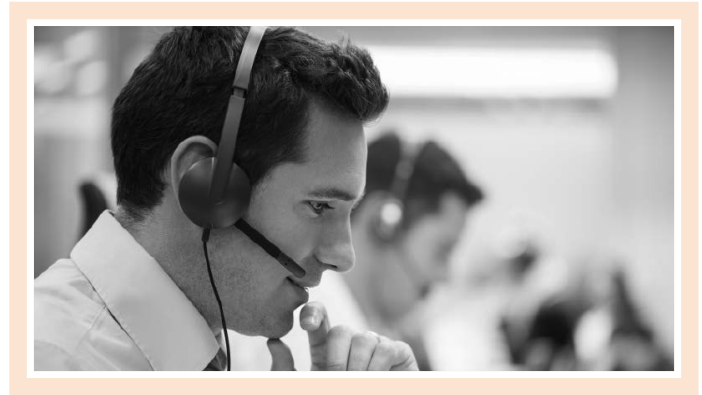


La evaluación diagnóstica es muy abstracta y no permite al maestro comprobar el grado en que el alumno ha asimilado las competencias básicas e implementar las medidas de seguimiento y mejora necesarias. Para el alumno también es frustrante al verse relegado al grado de los demás. La plataforma educativa Amic Professor se basaba en este tipo de evaluación en función de los criterios de PA y NM.

Algunas plataformas como Alexia incorporan las notas numéricas con la posibilidad de anotar comentarios adicionales para explicar los aspectos conductuales.

Además hay otro factor importante al defender la evaluación numérica frente a la diagnóstica y es el contraste o comparación de notas en los alumnos al realizar un seguimiento de su paso a la educación secundaria. Varios colegios concertados y públicos tienen acuerdos entre ellos, de forma que se autoadministran las notas de los alumnos que pasan de $6 .^{\circ}$ de primaria a $1 .{ }^{\circ}$ de ESO y cambian de centro. Con la comparación de notas observan si el alumno mantiene el nivel, algo que no sería posible si la evaluación diagnóstica continuara presente en la educación primaria.

El Ministerio de Educación ya indicó estas deficiencias en 2003, otorgando a las comunidades autónomas la elección de la conversión de notas tipo PA y NM en las antiguas notas numéricas. Conversión que fue aprobada por todas ellas. En dichas fechas, el ministerio remitió también a la Comisión General de Educación un proyecto sobre la atención educativa a los alumnos superdotados cuya atención estaba respaldada por la primera norma de la Ley orgánica de Calidad de la Educación (LOCE). No todos los alumnos excelentes son superdotados, pero la evaluación relativa respecto al grupo/clase puede detectar a estos alumnos «extraordinarios» en función de su situación dentro del mismo. Isaacs (1997) acentúa la necesidad de detectar a estos alumnos de la manera más precoz posible en el sistema educativo.

En definitiva, el panorama actual refleja que las distintas leyes de educación de estos años ya han ido modificando el concepto de «evaluación», concretando cada vez más las calificaciones que reciben los alumnos. La LOE ya ha manifestado que aun así continúan existiendo deficiencias en el proceso de detección de necesidades educativas especiales.

\section{(...) el panorama actual refleja que las distintas leyes de educación de estos años ya han ido modificando el concepto de "evaluación", concretando cada vez más las calificaciones que reciben los alumnos. La LOE ya ha manifestado que aun así continúan existiendo deficiencias en el proceso de detección de necesidades educativas especiales}

\subsection{La evaluación relativa}

Aparte de la evaluación numérica observada en el panorama actual, hay otro tipo de evaluaciones que no suelen verse en la educación primaria, pero sí en niveles más avanzados del sistema educativo, tales como la evaluación relativa, donde la calificación de un alumno depende de la nota media de su grupo de referencia.

La campana de Gauss es la gráfica de una función, la función gaussiana, que aparece en diferentes contextos como la función de densidad de la distribución normal o ley normal. Es una función que ayuda a comprender la probabilidad de que se den determinados valores dentro de una variable dada. La función gaussiana se define en honor a Gauss y permite observar, en la estadística y en la teoría de probabilidades, la función de densidad en una distribución normal, generando también unos valores habituales en cualquier población, tal como refleja el autor Canavos (1992) en su libro. lafrancesco (1995) incide en la necesidad de evaluar al alumno en relación con el ambiente en el que está siendo educado.

La distribución normal sigue unas ciertas características:

- Es simétrica respecto a su media.

- La moda y la mediana son ambas iguales a la media. 
- Los puntos de inflexión de la curva se dan en la misma medida según se alejen de la media por uno u otro sentido.

- La distribución de la probabilidad en un entorno de la media queda definido, de forma que:

- En el primer intervalo se encuentra comprendido el $68,26 \%$ de población.

- En el segundo intervalo se encuentra el $95,44 \%$ de población.

- En el tercer intervalo se encuentra comprendido el $99,74 \%$ de la población, creando intervalos de confianza. Los valores que se alejan de este intervalo son extraordinarios.

Alsina (2008) constata que la mayoría de distribuciones en la escuela aparecen reiteradamente en cada clase siguiendo la ley normal, con pocas notas excelentes y pocos suspensos. Esto es debido a que los profesores captan de forma inconsciente cuándo la clase no se acerca a la distribución normal de una curva de Gauss, y ello les hace sentirse incómodos porque dicha situación se aleja «de lo normal».

El matemático Antivi (2005) propone en su libro que el hecho de que la distribución sea normal implica que los profesores inconscientemente pueden estar modificando sus evaluaciones para que el resultado se acabe adaptando a la distribución normal y no sea tan incómodo. Antivi así nos da una referencia basada en su experiencia sobre cómo podemos estar ajustando las calificaciones a la distribución normal de la curva de Gauss. Este libro también lo utiliza explicando cómo aparece la desmotivación en los estudiantes debido a la forma en que se los etiqueta a veces, dando a entender que la aplicación inconsciente de la función de distribución normal de los maestros crea suspensos «necesarios» para que todo entre dentro de lo «normal». Este hecho ordinario viene de asumir que la distribución de cualquier grupo según la curva de Gauss se considera normal y deben aparecer casos de excelentes o suspensos por costumbre.

\section{(...) hay otro tipo de evaluaciones que no suelen verse en la educación primaria, pero sí en niveles más avanzados \\ del sistema educativo, tales como la evaluación relativa, donde la calificación de un alumno depende de la nota media de su grupo de referencia}

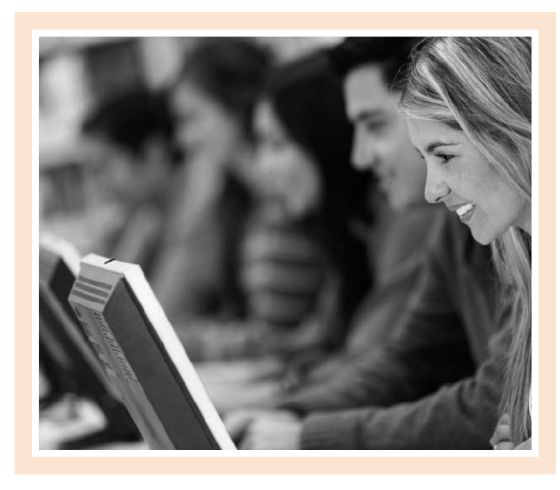

En el contexto escolar de educación primaria no se utiliza la campana de Gauss para evaluar, puesto que atentaría contra el derecho del alumnado a recibir una educación global e integral y en iguales condiciones a los demás, según Antivi (2005).

Si un alumno tuviera que obtener sus calificaciones en función de su comparación con los demás, su rendimiento decaería, puesto que siempre hay algún alumno peor que los demás, y la implantación de este sistema lo dejaría fuera del sistema educativo, atentando contra los principios básicos de escolarización establecidos por la LOGSE.

Los principios de la escolarización según la LOGSE se sustentan en:

- Principio de normalización. Consistente en poner a disposición de todos los estudiantes las mismas condiciones de estudio.

- Principio de integración escolar. Según el cual se unifica la educación especial y la ordinaria para ofrecer un conjunto de servicios a todos los niños en función de sus características.

- Principio de sectorización de la atención educativa. Aplicando la normalización a la prestación de servicios al alumno en el entorno en el que vive.

- Principio de la individualización de la enseñanza. Cada educando debe recibir la educación que necesita en cada momento de su evolución. 
Aplicar este sistema relativo de modo único para evaluar va en contra de los principios de la LOGSE, porque implica tratar a toda una comunidad de alumnos asumiendo que existan algunos con menos capacidades que el resto y que tratemos inconscientemente de localizarlos cuanto antes. La preocupación por localizarlos hace muchas veces que insistamos en la necesidad de que deben existir forzosamente en un grupo/clase, como sustentaba Alsina (2008).

La evaluación relativa se aplica en educación superior, como la universitaria, o en pruebas de oposición, como el acceso a policía, para puntuar las pruebas de educación física. El carácter de oposición de estas pruebas es muy distinto al de recibir una educación uniforme para todos $y$ el fin al que van encaminados estos procesos es el de buscar «a los mejores». En este caso, no atenta con los derechos de educación, al tener la LOGSE una vinculación a los sistemas educativos de escolarización obligatoria.

Sin embargo, aparte de su uso incorrecto, la evaluación relativa sí puede ser útil para ilustrar cómo un alumno destaca respecto al grupo/ clase y permite detectar casos de necesidades educativas especiales o sobredotación. No sería lo mismo observar a un alumno que saca excelente en todas las asignaturas que a un alumno que está un $60 \%$ por encima de la media de la clase en una asignatura.

Fleitman (2008) trata algo similar cuando describe el concepto de «beneficios» en una empresa. No es lo mismo una empresa que esté obteniendo un beneficio del $2 \%$ o del $4 \%$, dado que va en función del capital inicial utilizado. En educación puede utilizarse al ver una nota en función del grupo de referencia. Fleitman utiliza los conceptos de los términos relativos en vez de los absolutos para sintetizar y describir mejor la información que hay que utilizar.

Resumiendo, con la evaluación relativa los valores extremos no quedan tan enmascarados y es un buen complemento para comprobar cómo la clase queda distribuida de acuerdo a sus porcentajes, según se alejen más o menos de la media.

\section{(...) con la evaluación relativa los valores extremos no quedan tan enmascarados y es un buen complemento para comprobar cómo la clase queda distribuida de acuerdo a sus porcentajes, según se alejen más o menos de la media}

\subsection{La evaluación integral}

El concepto de «evaluación integral» parte de la necesidad de obtener una valoración lo más amplia posible del alumno, tal como describían Antivi (2005) y Casanova (1992) al hablar de las necesidades de obtener mayor información sobre el alumno, dado que en varios años los métodos no han cambiado.

Una determinada calificación no tiene el mismo significado en función del entorno o del grupo en que el alumno se eduque y tampoco según la asignatura y su dificultad.

Según Casanova (1992), la evaluación se asemeja al campo empresarial en el hecho de medir unos resultados de forma cuantitativa para observar el beneficio obtenido y utilizarse para ver los resultados de producción. Las teorías de Fleitman sobre la evaluación integral y su posibilidad de aplicación a todos los ámbitos se corresponden con la posibilidad de aplicar evaluación empresarial a los colegios.

En la conceptualización de evaluación integral, nos pueden ayudar determinadas teorías aplicadas al mundo de la empresa que reflejan el fondo al que se pretende llegar. La definición de «evaluación integral» según Fleitman (1992) se enmarca en una herramienta que permita valorar las áreas y los procesos de la empresa con un sistema constructivo, sistemático y científico que facilite tanto vigilar los procesos de producción como mejorarlos para elevar los niveles de eficiencia de la empresa.

Las deficiencias se pueden identificar en las áreas específicas de la empresa, cuya baja producción puede afectar a los objetivos generales de la misma. De modo que gracias a la información recogida por esta evaluación se pueden detectar con mayor precisión los puntos fuertes y débiles del estudiante, la clase o el propio colegio, pudiendo actuar de modo más eficaz para mejorarlos. 
De acuerdo con Fleitman (2008), la adecuada aplicación de la evaluación integral permite evaluar:

- El grado y la forma en que se cumplen los objetivos.

- Si son administrados con eficiencia, eficacia y economía los programas y recursos técnicos y materiales.

- La efectividad de las áreas y los procesos.

- La eficiencia del personal.

- Las fortalezas, debilidades, amenazas y oportunidades. Similar a los análisis DAFO utilizados en la empresa.

La revisión se puede hacer en un área o grupo de áreas, o en un «organismo» en su totalidad. Por ejemplo: al utilizarla se podría ver la distribución de acuerdo a la curva de Gauss en una determinada asignatura de cada curso. Observaríamos la asignatura de Matemáticas en cada curso y, en la mayoría, los notables estarían en torno a un $20 \%$, mientras que en otro curso estarían en un $40 \%$. Eso nos podría indicar un buen nivel de la clase o bien una excesiva permisividad del docente en cuestión, que se podría resolver contrastando la información de la calificación de cada alumno implicado, atendiendo a su trayectoria o tendencia.

Los criterios de medición previos son necesarios de establecer para hacer objetivas las bases de la evaluación, eliminando así cualquier criterio subjetivo y a ser posible estableciendo la evaluación en términos cuantificables para facilitar su interpretación según Fleitman (2008). Cada criterio de medición debe ser determinado en su periodicidad, base comparativa y unidad de medida, tal como decía Alsina (2008).

En un colegio la periodicidad se corresponde con los trimestres ordinarios, utilizando el mismo grupo/clase como base comparativa y la escala numérica y porcentajes como unidades de medida; también la relación entre el estudiante y la clase, definida en términos de desviación estándar y porcentaje.

\section{(...) ¿qué entendemos por evaluación integral del alumno? La habilidad de considerar la cualificación de notas del alumno en función de los estándares habituales numéricos, complementada con su progreso respecto a su grupo/clase por medio de la evaluación relativa}

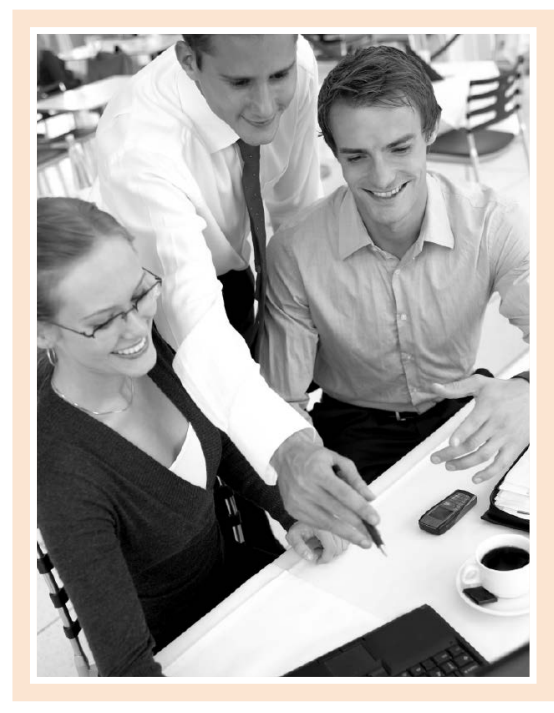

La evaluación integral presenta una serie de etapas al igual que cuando se implanta en una empresa. Etapas ya definidas por Fleitman (1993) en sus primeros trabajos sobre la evaluación integral.

1. Análisis preliminar.

2. Diagnóstico integral.

3. Diagnóstico específico de las áreas críticas.

4. Conclusiones y recomendaciones.

5. Implantación de recomendaciones.

6. Detección de mejoras obtenidas.

En una escuela, los pasos 1 y 2 se corresponden con evaluar las características de la plataforma educativa que poseen y la formación en TIC de los maestros para poder utilizarla además de las características del grupo/clase.

En el paso 3 de diagnóstico de áreas críticas las plataformas educativas habituales suelen presentar solo resultados en función del alumno, mientras que la plantilla ofimática desarrollada permite observar resultados para toda la clase y comprobar su mejora durante el curso teniendo en cuenta los progresos de los estudiantes que la componen. 
Estas posibilidades que ofrece permiten que los pasos $4,5 \mathrm{y}$ 6 de recomendaciones, implantación de estas y observación de lo obtenido puedan aplicarse no solo al alumno, sino también a toda la clase, al observar las asignaturas en las que más se está fallando y la distribución porcentual de notas. Los resultados porcentuales elevados en los extremos más bajos 0 altos de los estudiantes también darán indicaciones sobre la existencia de los alumnos con capacidades excepcionales o que necesitan educación especial personalizada. La detección de estos casos sería un primer paso, cuya confirmación se realizaría con otros recursos, como la trayectoria o tendencia del alumno o pruebas psicotécnicas llevadas a cabo por el psicopedagogo externo del colegio.

En conclusión, y respondiendo al primer objetivo secundario, ¿qué entendemos por evaluación integral del alumno? La habilidad de considerar la cualificación de notas del alumno en función de los estándares habituales numéricos, complementada con su progreso respecto a su grupo/clase por medio de la evaluación relativa.

La evaluación relativa teniendo en cuenta los criterios estadísticos de una distribución normal de una campana de Gauss no serviría como evaluación oficial. El concepto de «obtener la nota en función de la posición respecto a los demás» es contrario a normativas como el Real Decreto $696 / 1995$, donde se define la atención al alumnado aceptando sus diferencias y aplicando el principio de normalización en el aspecto educativo denominado «integración escolar». Pero la evaluación relativa sí será útil como información complementaria para comprobar el progreso del alumno/clase y como control del proceso de enseñanza/aprendizaje. Un alumno que suspende una asignatura continuamente puede presentar una mejora respecto al grupo/clase y ver cómo su nota, a pesar de ser un suspenso, se va acercando más a la media de la clase.

La evaluación relativa es útil al ser utilizada como complemento, pero no como una evaluación punitiva que castigue a los que quedan por debajo del grupo a pesar de esforzarse, porque siempre habrá alumnos con bajas calificaciones, y la calificación negativa, al «alejarse» del grupo, potenciará el sentimiento de baja autoestima.

Este tipo de evaluación siempre ha de ser para uso interno profesional y nunca exponerse a la vista de los padres en una entrevista de evaluación porque podría atentar contra los principios de la LOGSE sobre la evaluación del alumnado.

\section{RESULTADOS}

\subsection{Comparativa de las principales plataformas actuales}

Para responder al segundo objetivo específico de comparar los métodos o herramientas ofimáticas disponibles que gestionan la evaluación del alumno de primaria es necesario presentar las características fundamentales de las plataformas más utilizadas con la finalidad de diseñar una herramienta ofimática propia que permita tener una evaluación integral del alumno de primaria.

Estas son algunas plataformas educativas existentes en el mercado y sus ventajas e inconvenientes:

- Eleven. Plataforma que permite introducir notas, obtener medias numéricas, y cuya utilización se amplía hasta el punto de actividades como controlar el presupuesto del colegio o gestionar asignaturas vía on-line.

- Alexia. Parecida a la plataforma Eleven, pero sin la posibilidad de gestionar asignaturas vía on-line. Permite introducir numéricamente las calificaciones de los alumnos y también datos de asistencia del alumnado.

- Amic Professor. Esta plataforma tan solo cuenta con unos ficheros que contienen las asignaturas de cada maestro, donde se introducen las notas de forma categórica con códigos que representan, cada uno de ellos, una frase para describir al alumno. Está basada en el antiguo binomio PA/NM (progresa adecuadamente/necesita mejorar).

- Saga. Es la más utilizada en la escuela pública. Cuenta con la ventaja de permitir la introducción de notas numéricas y la obtención de medias. Tiene un funcionamiento simple, pero solo está disponible a final de trimestre para los docentes.

- PI. Las calificaciones de los alumnos son de forma numérica y con porcentajes. Puede modificarse a gusto del docente, para que él mismo pueda introducir el mayor 0 menor peso en porcentaje a determinadas actividades. 
Tabla 1. Comparativa de plataformas de control de calificaciones más relevantes del mercado

\begin{tabular}{|c|c|c|c|c|c|c|c|}
\hline & Concepto & Eleven & Alexia & Amic Professor & Saga & PI & Excel/Access \\
\hline \multirow{4}{*}{ Alumno } & Introducción de notas & Continua & Continua & A final de trimestre & A final de trimestre & Continua & Continua \\
\hline & Calificación & Numérica & $\begin{array}{l}\text { Numérical } \\
\text { Categórica }\end{array}$ & Categórica & Numérica & Numérica & $\begin{array}{l}\text { Numérical } \\
\text { Categórica }\end{array}$ \\
\hline & Media calificativa & Disponible & Disponible & No disponible & Disponible & Disponible & Disponible \\
\hline & Desviación estándar & No disponible & No disponible & No disponible & No disponible & No disponible & Disponible \\
\hline \multirow{3}{*}{ Clase } & Alumno/Clase & No disponible & No disponible & No disponible & No disponible & No disponible & Disponible \\
\hline & Media & No disponible & No disponible & No disponible & No disponible & No disponible & Disponible \\
\hline & Distribución porcentual & No disponible & No disponible & No disponible & No disponible & No disponible & Disponible \\
\hline \multirow{2}{*}{ Asistencia } & Control diario & Disponible & Disponible & No disponible & No disponible & No disponible & Disponible \\
\hline & Numero total de ausencias & Disponible & Disponible & No disponible & No disponible & No disponible & Disponible \\
\hline \multirow{2}{*}{ Informes } & Informes individualizados & Disponible & Disponible & No disponible & No disponible & Disponible & Disponible \\
\hline & Progreso del alumnado & No disponible & No disponible & No disponible & No disponible & No disponible & Disponible \\
\hline \multirow{4}{*}{ Sistema } & Precio & Coste & Coste & Coste & Coste & Coste & Sin coste \\
\hline & Conocimientos de informática & Medios & Medios & Básicos & Básicos & Básicos & Básicos \\
\hline & Requerimientos técnicos & Ordenador/ Intranet & Ordenador/ Intranet & Ordenador & Ordenador/Intranet & Ordenador/Intranet & Ordenador \\
\hline & Seguridad y compatibilidad & Personalizado & Personalizado & Personalizado & Personalizado & Personalizado & $\begin{array}{c}\text { No } \\
\text { personalizado }\end{array}$ \\
\hline
\end{tabular}

\begin{tabular}{l|l|l|l} 
Defecto/Falta & Neutro & Ventaja/Posibilidad & Fuente: elaboración propia. \\
\hline
\end{tabular}

La evaluación integral del alumno se dividiría en cinco apartados:

- Alumno. Valoración individual del alumno. La mayoría evalúan en función de un indicador numérico, mientras que la plataforma Amic Professor evalúa tomando como base las categorías. Esta plataforma tiene el inconveniente de no poder introducir notas a medida que el curso avanza, dejando tan solo el último tramo del trimestre para hacerlo. El maestro únicamente puede ver un breve feedback del alumno al final. Excepto en el caso de la plataforma Amic Professor, en el resto sí es posible encontrar alguna media calificativa del alumno, sea del trimestre o del curso. La plantilla se diseñaría para poder introducir notas en cualquier momento del curso y observar la calificación del alumno en ese instante.

- Clase. Observar notas del alumno respecto a su clase y medias del grupo en general, analizando las asignaturas más difíciles para el grupo. Ninguna de las plataformas permite observar medias de la clase en las distintas asignaturas ni observar una distribución de notas y porcentajes de alumnos. En este caso, la plantilla de Excel/Access y sus posibilidades superan estos inconvenientes que presentan las plataformas habituales al no existir una valoración general del grupo clase.

- Asistencias. En el apartado de asistencias las plataformas que permiten su interactividad durante el curso, como Eleven o Alexia, admiten introducir las ausencias a medida que se producen. Otros sistemas como Amic Professor o Saga, al estar restringido el acceso durante el curso, no permiten que los maestros tengan constancia al momento de las ausencias de los alumnos ni tampoco sobre su cantidad total durante el curso. En este caso, el diseño de la plantilla Excel/Access mantendría las mismas posibilidades que las otras plataformas educativas convencionales, con la mejora de que el maestro podría observar en cualquier momento del curso el contador de ausencias, así como otros datos similares, tales como el diario de clase y la puntualidad. 
- Informe individualizado del alumno. Este punto se refiere a la posibilidad de ver una ficha resumen del alumno con sus calificaciones. Las plataformas Eleven y Alexia admiten observar por separado al alumno y sus notas cuantificadas, pero no se obtiene ningún índice de progreso o mejora objetivo. Las plataformas Amic Professor y Saga no permiten la opción individualizada del informe de un alumno, excepto al introducir las notas correspondientes.

La plantilla Excel/Access permitiría ver el informe detallado de cada alumno tanto en conjunto con los demás, como en forma individual, mediante la opción de formularios de Access. Además, se podrían crear gráficos específicos para un alumno en concreto, observando su progreso de mejora, y compararlo con otros.

- Sistema. Con respecto a las características del sistema se analizan cuestiones relacionadas con la evaluación y las posibilidades que ofrece a nivel técnico. Los distintos matices aquí están más centrados en la cantidad de almacenaje del sistema, el tiempo de gestión, sus formatos, su compatibilidad con otros formatos para traspasar datos, su accesibilidad y su posibilidad de ser empleado por el docente en cualquier momento $o$ tan solo en el entorno habitual del colegio. En varias plataformas como Amic Professor y Saga este factor limita a los maestros, puesto que no pueden introducir datos hasta final de curso, mientras que en otras plataformas el docente puede ir adelantando trabajo al respecto, introduciendo las notas en forma de evaluación continua. En otras plataformas como Eleven o Alexia la posibilidad de introducir continuamente los distintos datos sitúa su tiempo de gestión al mismo nivel que las posibilidades de la ofimática.

En definitiva, y como conclusión del segundo objetivo, tras la comparación de las plataformas más representativas disponibles para la gestión de la evaluación del alumno de primaria, se han detectado varios inconvenientes, siendo los más importantes:

- Imposibilidad de introducción de notas de forma continua.

- Ausencia de representación de datos de las calificaciones de la clase y del progreso del alumno respecto a ella.

- Un mayor coste en la implantación de las demás plataformas.

\subsection{Plantilla ofimática}

Una vez que se han descrito los principales inconvenientes que presentan las plataformas más habituales y teniendo en cuenta el concepto de «evaluación integral» como se definió en el marco teórico, se procede a responder al tercer objetivo específico: diseñar una herramienta ofimática propia mediante los programas Access/Excel para la evaluación integral del alumno que mejore y complemente las herramientas actuales.

\subsubsection{Diseño}

La plantilla ofimática realizada combina Excel y Access, dos programas integrados dentro de Microsoft Office, considerado un estándar en ofimática que prácticamente está presente en cualquier ordenador y permite generar bases de datos.

Excel admite el desarrollo de bases de datos como Access, pero, además, añade funciones automatizadas, de forma que al introducir unos valores se generen otros nuevos en función del cálculo realizado. Así, no es necesario rehacer los cálculos cada vez que se introducen datos o se modifican los ya existentes.

Access permite unas funciones de catálogo de datos superiores y que visualizan las bases de datos creadas en forma de informes, catálogos de bibliotecas o bases de datos ordinarias. Tiene también funciones de consulta o búsqueda para mostrar tan solo los datos que se quieren observar de toda una tabla.

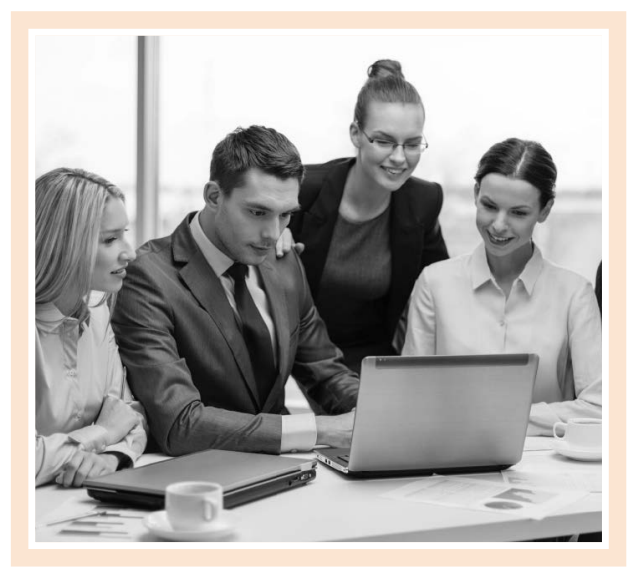


En las plantillas de evaluación Excel se generan datos estadísticos sobre la distribución normal de la clase, cálculos a partir de las asistencias de los alumnos, y los transfiere a Access, que muestra los datos recopilados de los estudiantes. La plantilla de Access está directamente enlazada, de forma que se actualiza constantemente a medida que la de Excel se modifica y recoge todos los datos obtenidos para mostrarlos de forma más resumida y funcional.

Cualquier modificación de dato o valor siempre ha de realizarse en las tablas de Excel y su cambio se verá reflejado en las tablas de Access pero al cambiar algún aspecto de su diseño sería necesario volver a vincular la tabla de Access con las originales.

\subsubsection{Descripción}

Se presentan tres tipos de recopilación de datos:
A) Una plantilla de Excel con notas del alumno (Alumno)

En esta se presentan cinco hojas de cálculo: una por cada trimestre, una como resumen del curso y una individual, presentando a cada alumno aislado (véase figura 4).

Las cuatro primeras hojas están distribuidas en tres partes:

- Nota de los alumnos en las asignaturas.

- Índice de desviación estándar de cada alumno en cada asignatura.

- Nota categórica del alumno en función de su índice de desviación estándar.

En las cuatro primeras hojas, en la parte inferior, están los resúmenes de la primera y tercera parte, con dos gráficos.

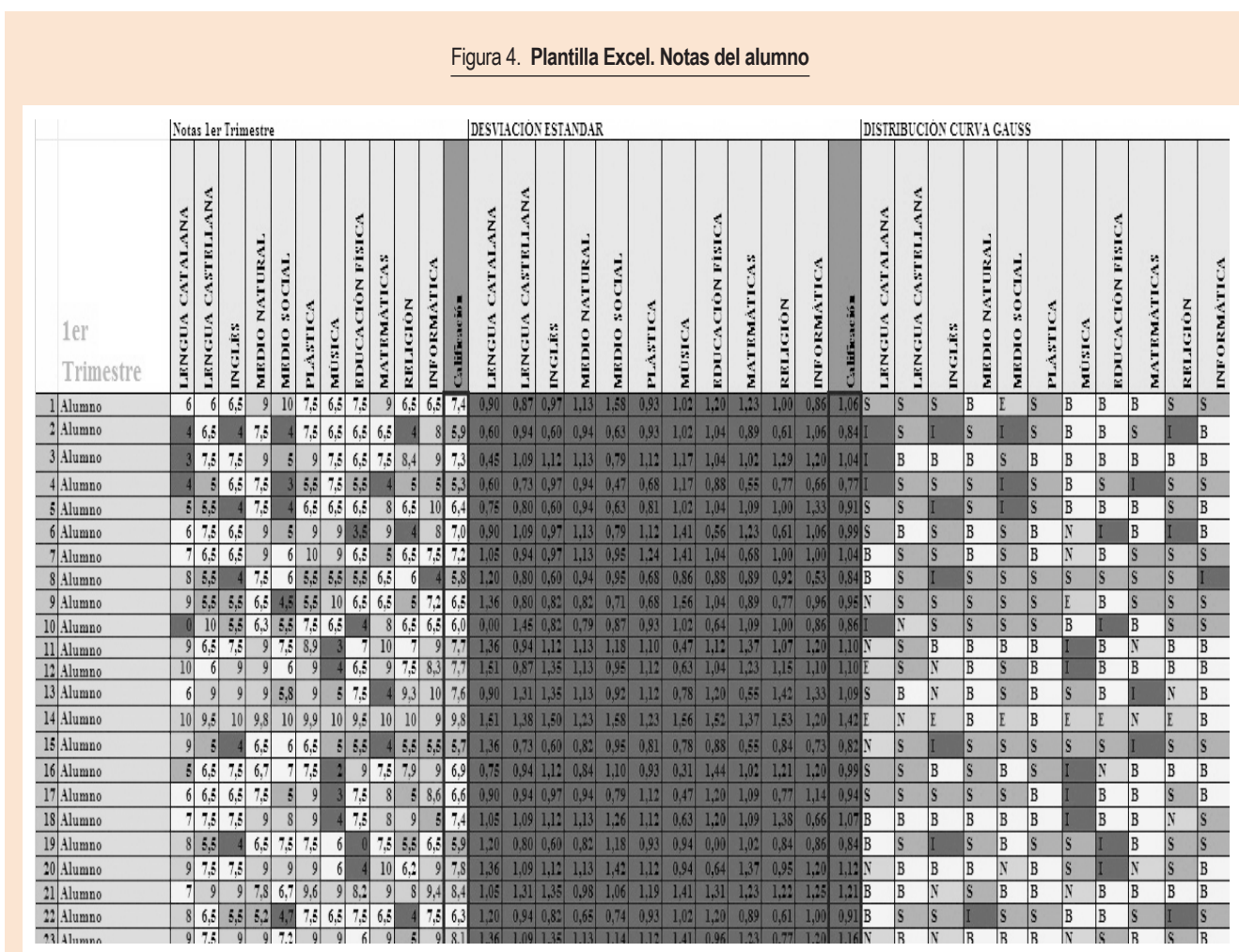

Fuente: elaboración propia. 
El primer resumen presenta el número ordinario de excelentes, notables, bienes, suficientes, insuficientes y no evaluados de la asignatura, junto a un gráfico que muestra su distribución (véase figura 5).

El segundo resumen presenta el número de alumnos que se encuentran incluidos en cada tramo de porcentaje de la clase según la curva de Gauss y también muestra un gráfico que presenta su distribución.

Tenemos cuántos alumnos están presentes en cada uno de los tramos habituales de la curva de Gauss: $15,8 \%, 33,4 \%, 50 \%, 84,1 \%, 97,6 \%$ y $99,7 \%$.

Las notas categóricas se distribuyen de la siguiente forma:

- Insuficiente. Cualquier alumno comprendido entre el $0-15,8 \%$ de la clase.

- Suficiente. Cualquier alumno comprendido entre el $15,81-50 \%$ de la clase.
- Bien. Cualquier alumno comprendido entre el $50,1 \%$ $-84 \%$ de la clase.

- Notable. Cualquier alumno comprendido entre el $84,1-97,6 \%$ de la clase.

- Excelente. Cualquier alumno comprendido entre el $97,6-99,7 \%$ de la clase.

- Matrícula de honor. El alumno comprendido entre el 99,71 y $100 \%$ de la clase.

Las notas de suficiente y bien se corresponden con el conjunto de $68,2 \%$ presente en una primera desviación estándar en una distribución normal ordinaria. La matrícula de honor es simbólica, pero permite descubrir a alumnos que realmente han sido brillantes en una asignatura difícil para el resto, siendo alumnos con un valor de un $60 \%$ por encima de la clase.

Figura 5. Distribución de notas y porcentajes. Distribución de calificaciones

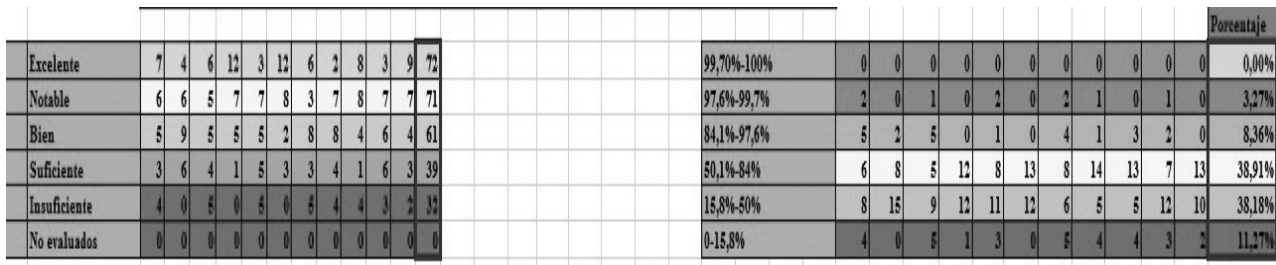

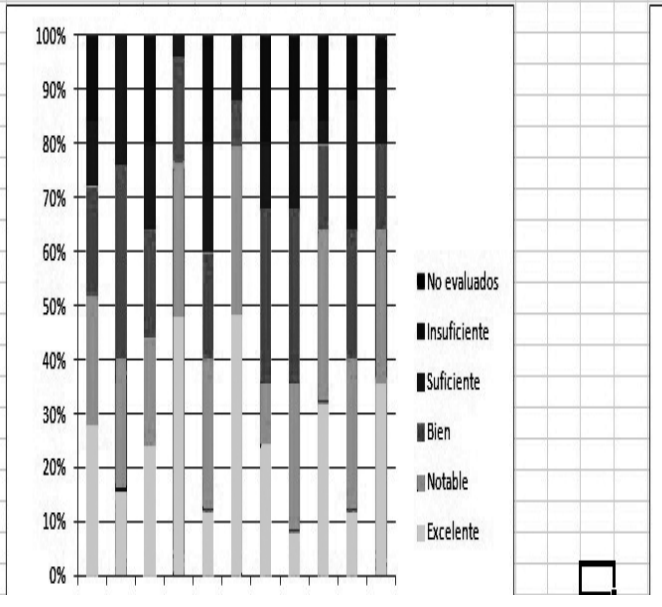

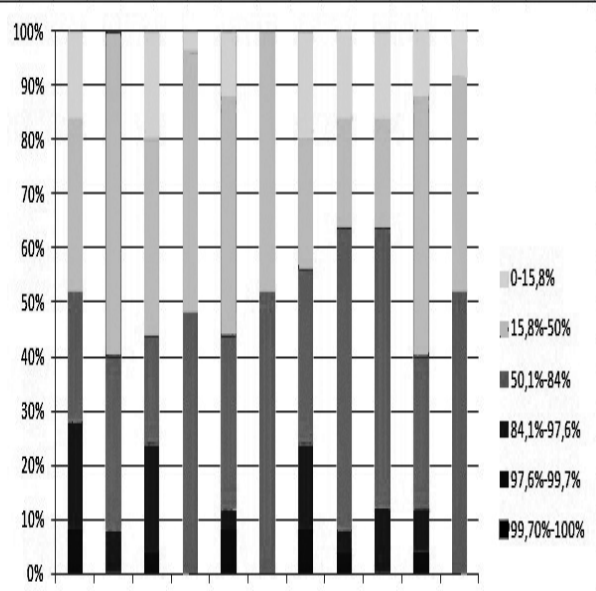


En la quinta hoja aparece cada alumno con sus notas, su índice de desviación estándar y su calificación según su distribución porcentual en la curva de Gauss en cada trimestre. De esta forma se puede ver la evolución de cada alumno tanto a nivel de calificación como dentro de la clase (véase figura 6).

B) Una plantilla de Excel de ausencias y control del diario del alumno (Ausencias)

La plantilla está formada por dos hojas: una, en la que salen los meses al detalle, y otra, con el resumen de los trimestres, del curso y de los valores máximos de cada alumno en cada apartado. En dicha plantilla aparece una distribución de cada mes dividido en semanas, que podrá modificarse con las opciones de Excel según el calendario anual de cada curso (véase figura 7).

En las casillas se han de introducir diferentes letras según una codificación propia: diario no firmado (D), retardo de mañana $(R M)$, retardo de tarde (RT), ausen- cia de mañana (M), ausencia de tarde $(T) 0$ ausencia de todo el día (MT). Debajo de cada columna, con la opción de «insertar comentario», se puede introducir una pequeña anotación, tan solo visible cuando estamos encima de la casilla, que permite anotar los incidentes del día tanto en deberes no hechos como en ausencias a mitad de clase por ir al médico 0 similares.

La hoja tiene un resumen final que recoge automáticamente los valores generales de cada mes y cada trimestre.

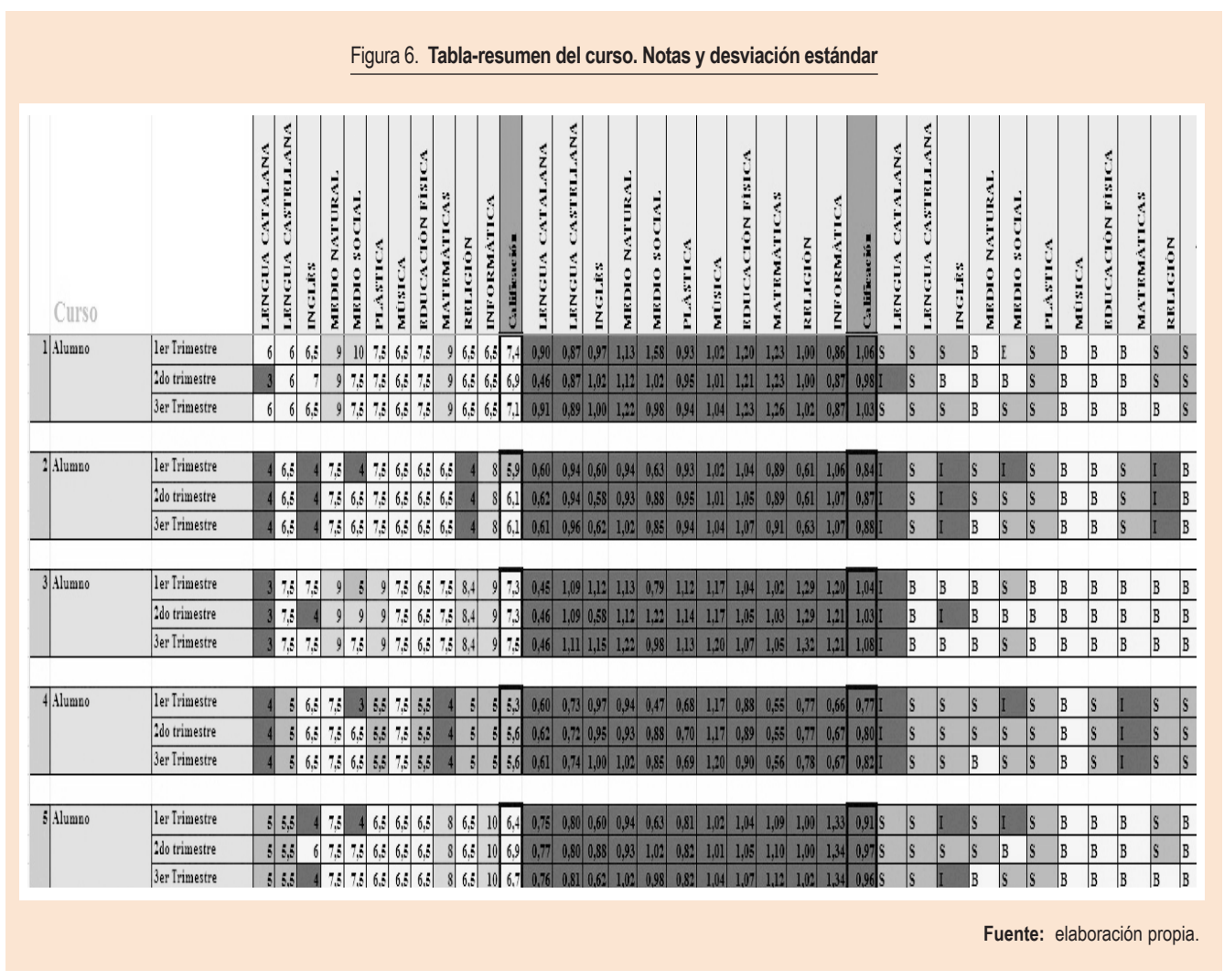




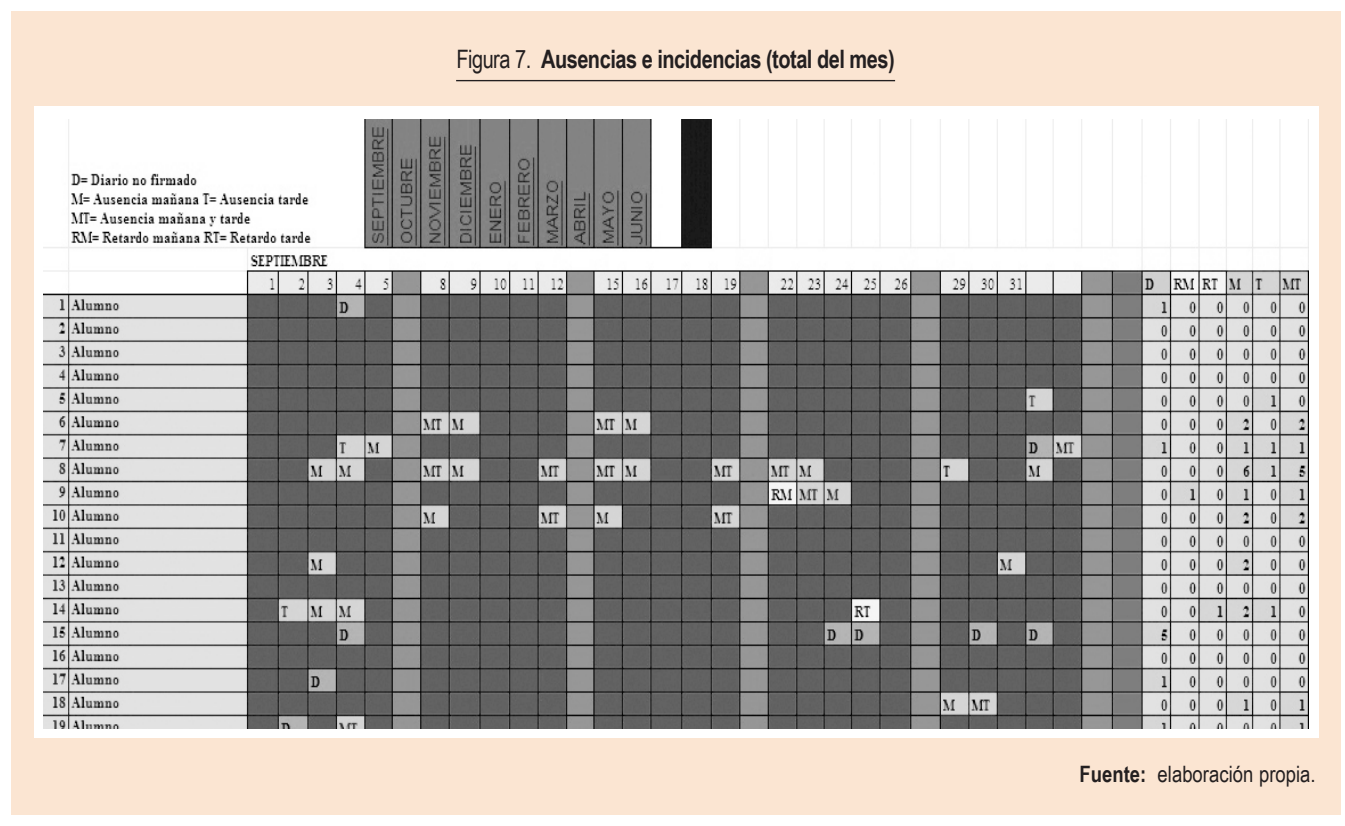

\section{C) Una plantilla de Access enlazada a las dos anteriores de Excel}

Recoge los resultados a partir de la hoja Alumno de la primera plantilla y a partir de la hoja Asistencia de la segunda plantilla. En la plantilla de Access se muestran tres representaciones de cada hoja enlazadas:

- Una primera, en la que aparece como base de datos cada hoja (véase figura 8).

Figura 8. Plantilla Access. Tabla de datos de notas del alumno

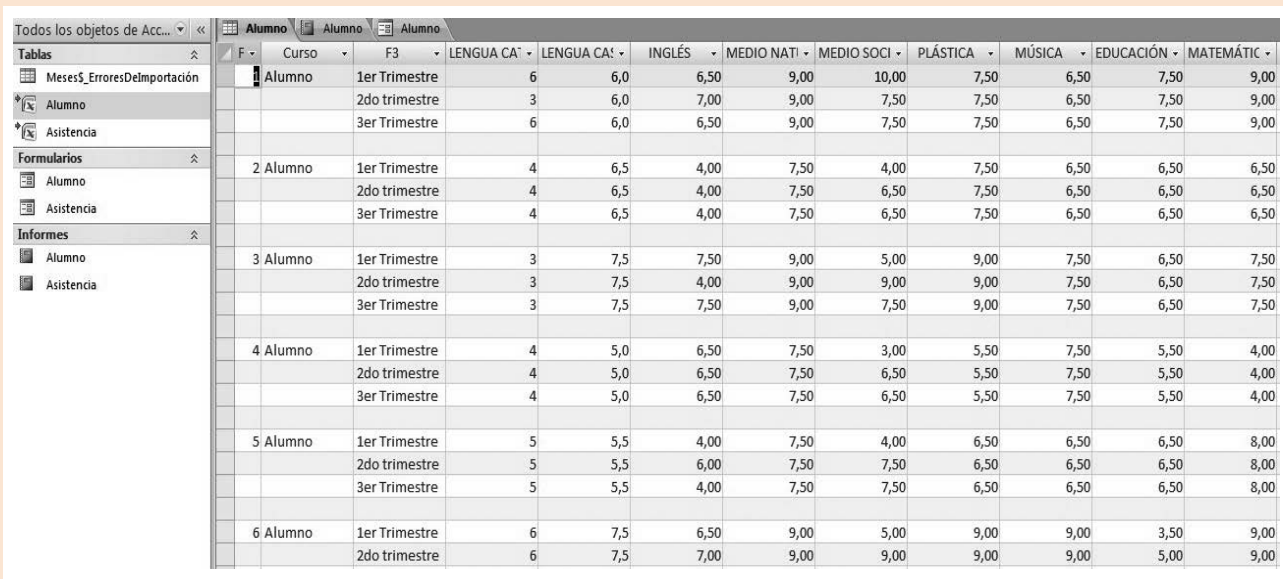


- Una segunda, en la que aparecen como formulario. Una opción que permite ver los valores en forma de etiquetas similares a las que se pegan en los paquetes que hay que enviar por correo (véase figura 9).

- Una tercera, en la que aparecen como informe, opción que permite ver en forma de datos todo lo representado (véase figura 10).

El resultado final son tres plantillas que se van configurando continuamente tan solo a partir de que el maestro introduzca las notas de cada trimestre y la actividad diaria del alumno respecto a las ausencias e incidencias diarias.

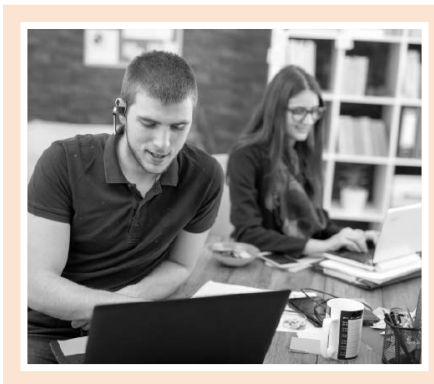

Figura 9. Plantilla Access. Formulario de notas del alumno

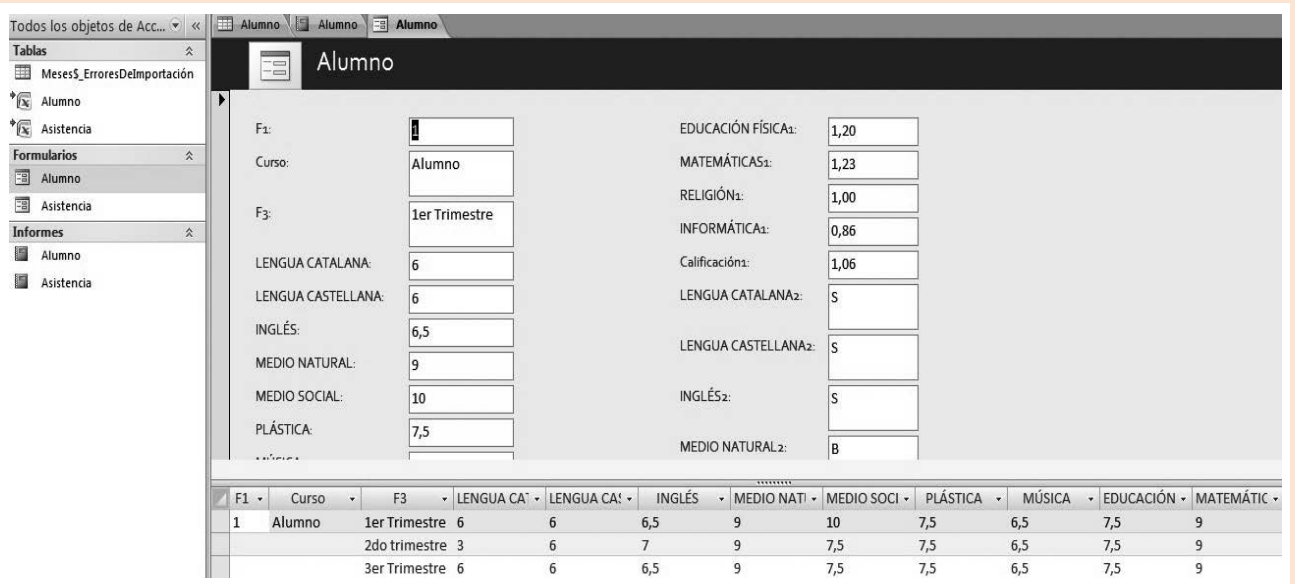

Figura 10. Plantilla Access. Informe de notas del alumno

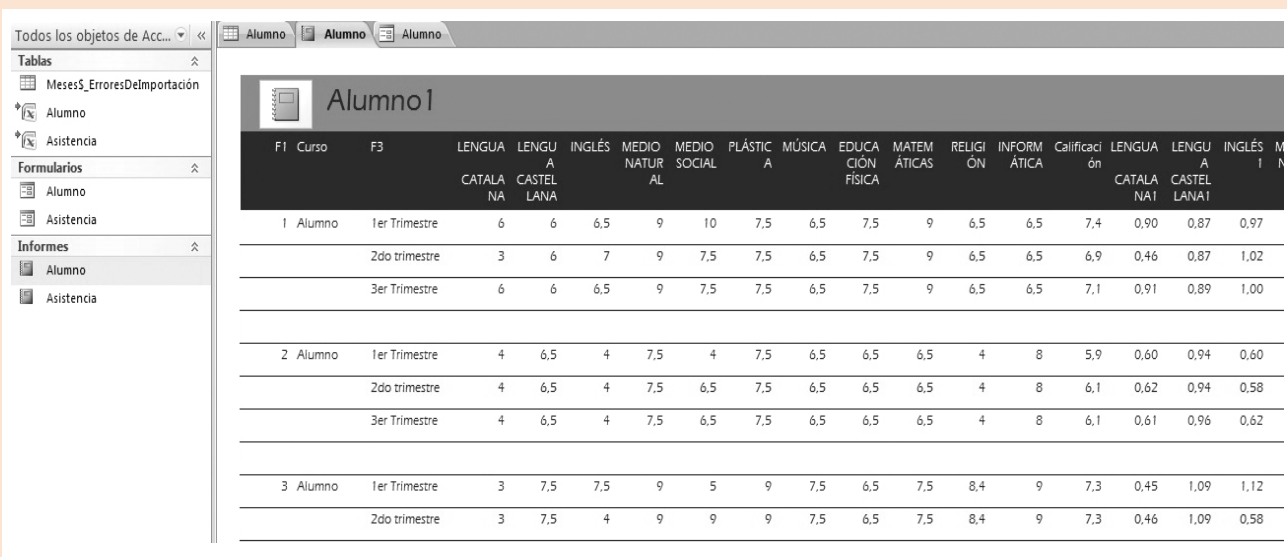




\subsection{Funcionalidades de la plantilla}

Las funcionalidades ofrecidas por la plantilla nos permiten ver mucha más información del grupo/clase que en una plataforma de introducción de notas normal, con bastante menos trabajo. Esta plantilla puede ser utilizada conjuntamente con la plataforma habitual, substituyendo el cuaderno escolar ordinario del maestro. Las funcionalidades que no dan las otras plataformas son:

- Desviación del alumno respecto a la media de la clase en una asignatura concreta.

- Nota del alumno de acuerdo a su desviación de la media de la clase.

- Media del alumno en la calificación de todas las asignaturas.

- Media de la desviación del alumno en la calificación de todas las asignaturas.

- Número de excelentes, notables, bienes, suficientes, insuficientes y no evaluados del grupo/clase en asignaturas concretas.

- Número de excelentes, notables, bienes, suficientes, insuficientes y no evaluados del grupo clase según la calificación estadística de los alumnos.

- Gráficos con los porcentajes de la clase divididos.

- Media del alumno del curso en las asignaturas y en su desviación estándar en cada aspecto.
- Media de la clase del curso en cada asignatura y en su distribución porcentual según las calificaciones.

- Los resultados de ausencias y su cuantificación sí se dan en otras plataformas.

- Al contrario que otras plataformas, esta plantilla permite ser transmitida de tutor a tutor cuando se da información sobre una clase.

La desviación estándar es la principal novedad que ofrece la plantilla de ofimática y que las otras plataformas educativas no pueden mostrar.

Todas las ventajas obtenidas pueden utilizarse para un curso concreto y una serie de asignaturas, pero también se podría acotar al detalle dentro de uno mismo de esos campos educativos para observar el comportamiento y la puntuación obtenidas en una asignatura concreta.

La plantilla se puede utilizar para evaluar una asignatura substituyendo las asignaturas por títulos del estilo de «Examen 1», «Examen 2», etc., de forma que nos presenta las mismas valoraciones estadísticas pero dentro de una asignatura concreta y en cada examen o ejercicio puntuable de clase realizado (véase figura 11).

Al modificar las asignaturas por exámenes o ejercicios que se realicen dentro de una asignatura, la plantilla podría darnos el mismo efecto de ver a cada alumno comparado con los demás en cada concepto de clase.

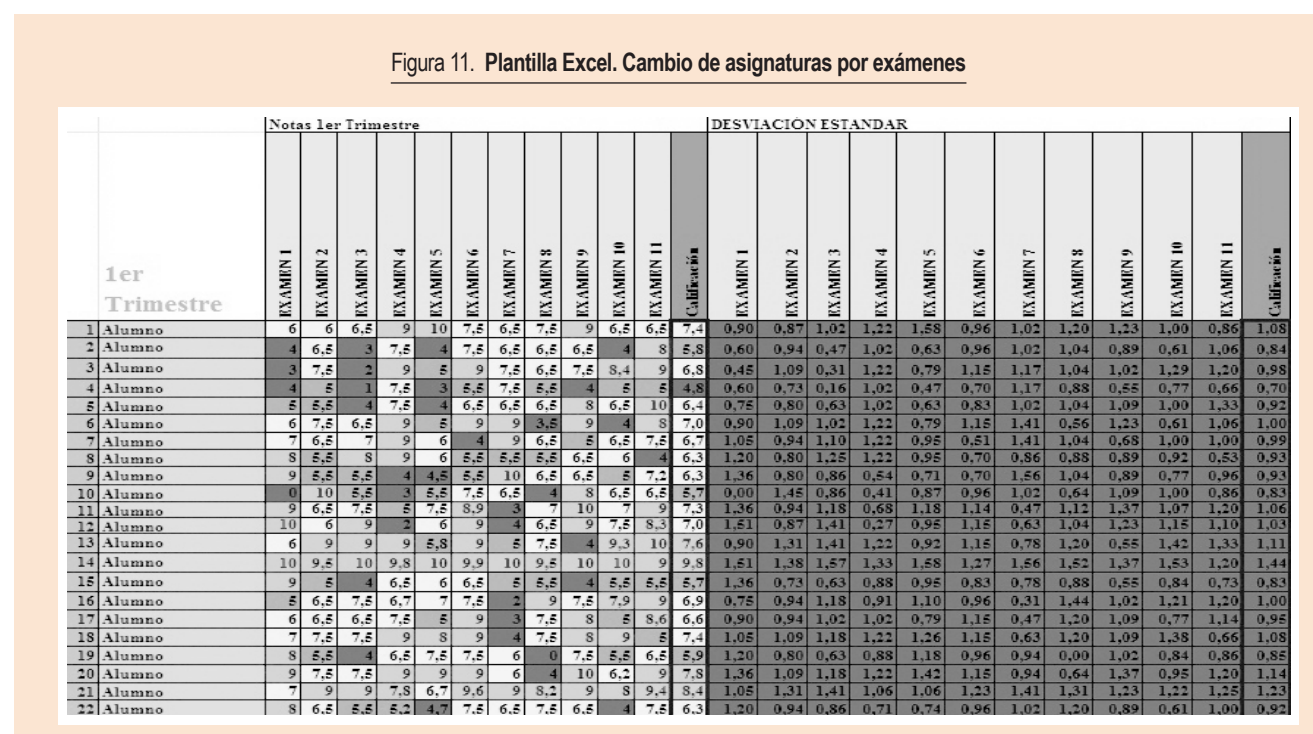

Fuente: elaboración propia 
Esto quiere decir que también existe la posibilidad de crear una plantilla de este tipo por cada asignatura de los alumnos para controlar aún más los ejercicios evaluativos y comprobar los exá-

\subsection{Obtención de tendencias del alumnado}

Además Excel incorpora la posibilidad de crear gráficos que podrían aplicarse a un alumno concreto en un momento para observar su evolución de manera gráfica e incluso realizar alguna predicción o tendencia al introducir un gráfico particular que otorga directamente la fórmula de la recta que se obtiene de la tendencia según la distribución de las calificaciones obtenidas.

En la siguiente figura se ha creado un gráfico que muestra las distintas calificaciones obtenidas del alumno 1 tanto en calificaciones de exámenes (véase figura 12) como en desviación respecto a la media de la clase (véase figura 13).

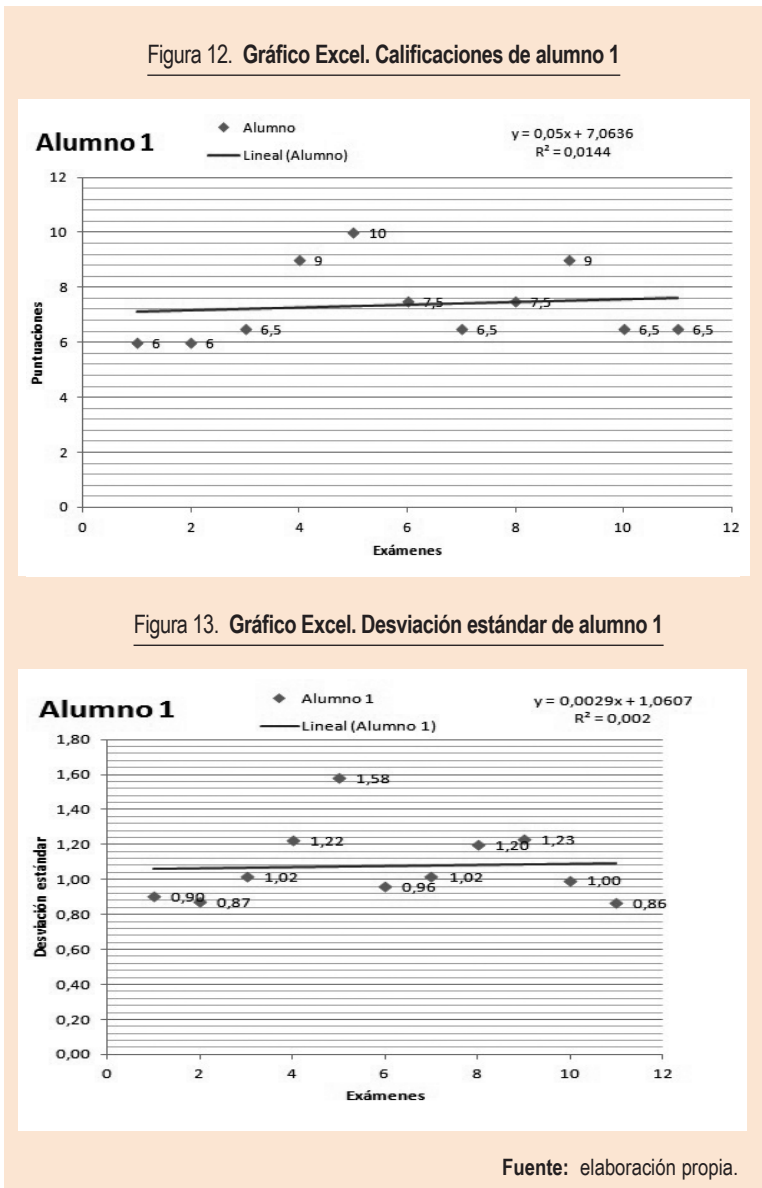

menes que han costado más a la clase y los conceptos que conviene repasar en un futuro.

Se muestran las calificaciones obtenidas en los distintos exámenes y también la línea de la tendencia. La línea de la tendencia da una fórmula que en este caso es $Y=0,05 x+7,0636$. Esta fórmula es una medida de predicción que si la aplicáramos, nos diría aproximadamente en torno a que nota va a rondar el siguiente examen del alumno.

La correlación o coeficiente de correlación r2 mide el grado de relación entre las variables utilizadas y su fiabilidad al intentar predecir un resultado aplicando la ecuación de la recta. Su valor puede oscilar entre -1 y 1 , dando un grado de intensidad de la correlación perfecta de forma directa o inversamente proporcional.

Con la fórmula de la recta obtenida se podría intentar predecir la nota que el alumno sacaría en el examen número 12 , cuyo resultado todavía no ha aparecido en el gráfico.

La nota predicha según la fórmula de la recta para el alumno cuando realice el examen número 12 sería un 7,66 , pero el valor de correlación bajo indicaría una escasa probabilidad de que se cumpla. No obstante, nos indicaría qué nota aproximada podemos esperar de ese alumno.

$$
\begin{aligned}
& \text { Ejemplo } 1 \\
& \text { Examen } 12 \quad Y=0,05(12)+7,0636 \\
& Y=7,6636
\end{aligned}
$$


En este caso se observa la evolución del alumno en su desviación estándar, es decir, en la medida en que se aleja de la media de la clase, cuyo valor es 1 .

Nuevamente aparece una fórmula que nos da una tendencia, que en este caso es $Y=0,0029 x+1,0607$. El cálculo de esa fórmula con la variable de examen 12 nos permitirá ver en torno a qué media respecto a la clase se moverá el alumno en su examen siguiente.

\section{Ejemplo 2}

$$
\text { Examen 12 } \begin{aligned}
Y & =0,0029(12)+1,0607 \\
Y & =1,0955
\end{aligned}
$$

$\mathrm{R} 2=0,002$, que indica poca correlación entre las dos variables y poca fiabilidad de la predicción.
El valor de 1,09 indicaría que el alumno se alejaría poco de la nota media de clase de valor $1, y$ dicha nota puede ser también predictiva de su rendimiento.

Esta es una muestra de cómo otros cálculos se podrían aplicar a la plantilla para obtener aún más datos predictivos de los alumnos. Y esto es solo un ejemplo de la multitud de cálculos que podrían realizarse.

En la comparación entre plataformas educativas vemos cómo la plantilla de Excel/Access permite más posibilidades que otras en el aspecto evaluativo.

También tiene desventajas, como la seguridad y la personalización de la plantilla respecto a otras, aunque también tiene las opciones de proteger la plantilla creada y configurarla según una contraseña de acceso que personalizaría cada plantilla generada para cada maestro. Incluso utilizando el Google Drive, un servicio del buscador de Internet Google que permite alojar archivos de forma pública, se podrían alojar las plantillas de cada clase en internet, restringidas por medio de contraseñas a sus usuarios correspondientes, favoreciendo así la conectividad remota.

La evaluación integral del alumno se apoya en su gestión a través de la plantilla generada con ventajas frente a las plataformas habituales en cada uno de los cinco grandes apartados realizados (véase tabla 2).

\section{Tabla 2. Comparación. Ventajas de la plantilla ofimática}

\begin{tabular}{|c|l|l|}
\hline \multirow{2}{*}{ Alumno } & $\begin{array}{l}\text { Ventajas } \\
\text { - Calificaciones relativas respecto a la clase. } \\
\text { - Visuación respecto a la media de la clase. }\end{array}$ \\
Clase & $\begin{array}{l}\text { - Distribución de progreso y predicción. } \\
\text { - Obtención de medias por asignatura. }\end{array}$ \\
Asistencia & $\begin{array}{l}\text { - Visualización diaria de las faltas de asistencia. } \\
\text { - Control de faltas de asistencia y retardos. }\end{array}$ \\
Informes & $\begin{array}{l}\text { - Presentación individualizada de todos los datos resumen del alumno. } \\
\text { - Visualización de las calificaciones obtenidas y de faltas de asistencia de forma conjunta. }\end{array}$ \\
Sistema & $\begin{array}{l}\text { - Sin coste adicional, sin necesidad de conocimientos informáticos previos y con posibilidad de ser personalizado e implantado } \\
\text { vía on-line. }\end{array}$ \\
\hline
\end{tabular}

Fuente: elaboración propia. 
El funcionamiento de la plantilla Excel/ Access no solo da una muestra de la cantidad de información que se puede extraer de una clase y que las plataformas no aprovechan, sino que también muestra cómo una sencilla aplicación de la ofimática nos puede dar tanta 0 más información que las plataformas educativas actuales

El funcionamiento de la plantilla Excel/Access no solo da una muestra de la cantidad de información que se puede extraer de una clase y que las plataformas no aprovechan, sino que también muestra cómo una sencilla aplicación de la ofimática nos puede dar tanta o más información que las plataformas educativas actuales. Además, el ahorro de tiempo que permite a la hora de obtener información y trasladarla, dándosela a un tutor, sobre el comportamiento de una clase es muy favorecedora para el trabajo.

La detección de sobredotación es más factible con este sistema para distinguir a los alumnos que simplemente sobresalen de los que obtienen valores extremos.

Podemos comparar los resultados obtenidos con el resto de plataformas educativas antes analizadas para ver hasta qué punto nos facilita la información y en qué aspectos es más ventajosa la utilización de esta plantilla al respecto de las ordinarias.

Otro inconveniente que también poseen las plataformas es que muchas veces han de «activarse» desde secretaría para los maestros, y eso causa que muchos no puedan adelantar trabajo. Algunas permiten trabajar con ellas interactivamente durante todo el curso en cualquier momento, pero otras tan solo se abren al final de los trimestres para que se introduzcan las evaluaciones correspondientes, como la antigua plataforma Amic Professor y Saga. En estos casos, el maestro ha de recurrir durante el curso a su propio cuaderno escolar para anotar calificaciones y tan solo introducirá la nota final sin que pueda ver en algún momento del curso información de su propia clase.

Como conclusión al tercer objetivo específico, se ha diseñado una herramienta ofimática propia, mediante los programas Access/Excel, para la evaluación integral del alumno, que mejora y complementa las herramientas actuales.

\section{CONCLUSIONES}

A lo largo del trabajo, se han respondido las diferentes cuestiones a las que hacian alusión los objetivos secundarios planteados, con las siguientes conclusiones:

- Se ha definido conceptualmente la «evaluación integral» del alumno de primaria como la habilidad de considerar la cualificación de notas del alumno en función de los estándares habituales numéricos, complementada con su progreso respecto a su grupo clase por medio de la evaluación relativa.

- Se han comparado las plataformas más representativas disponibles para la gestión de la evaluación del alumno de primaria detectándose principalmente tres problemas:

- Imposibilidad de introducción de notas de forma continua.

- Ausencia de representación de datos de las calificaciones de la clase y de progreso del alumno respecto a ella.

- Un mayor coste en la implantación de las demás plataformas.

- Se ha diseñado una herramienta ofimática propia mediante los programas Access/Excel para la evaluación integral del alumno mejorando los aspectos de datos calificativos tanto del alumno como de la clase, la visualización de los progresos de la clase y el alumnado, y, finalmente, para la detección tanto de dificultades en asignaturas como de alumnos con necesidades educativas especiales.

La conclusión principal del trabajo es que se ha generado una herramienta ofimática propia para la gestión de la evaluación integral del alumno de primaria.

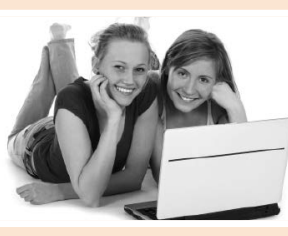




\section{La conclusión principal (...) es que se ha generado una herramienta ofimática propia para la gestión de la evaluación integral del alumno de primaria}

\section{PROSPECTIVA}

La prospectiva de este trabajo se ha dividido en dos apartados: la tendencia de las plataformas educativas actuales de introducción de notas y la tendencia de la informática en las aulas. Es interesante ver en un futuro próximo cómo pueden evolucionar las TIC en la utilización educativa y la proyección del docente al respecto de su manejo.

\subsection{Plataformas educativas}

La tendencia actual de las plataformas educativas ha cambiado en los últimos años. Se ha pasado de plataformas como Amic Professor, que daba las valoraciones de forma categórica con frases en vez de notas numéricas, a programas como Pi o Alexa que vuelven a puntuar las asignaturas con números. Algunas de estas plataformas incorporan nuevas funciones, como el control de ausencias y la programación de entrevistas con padres, pero siguen sin introducirse unos sistemas de evaluación general de la clase.

Las plantillas realizadas pueden servir como substitutorio del cuaderno escolar del maestro y agilizan el trabajo. Las que aquí se han mostrado son un ejemplo, pero también podrían realizarse otras muchas que agilicen procesos, como cuando el maestro pone las notas de la asignatura en función de criterios de evaluación y ha de poner notas siguiendo baremos, como un $60 \%$ de nota de examen, un $20 \%$ de nota de libreta, un $10 \%$ de esfuerzo y un $10 \%$ de actitud. Son cálculos que de cabeza o con una calculadora quitan mucho tiempo y que también pueden programarse con Excel, de forma que al introducir los números en cada campo los cálculos se realicen solos.

La evolución y las TIC se imponen, y recursos como este son un complemento a la labor diaria en clase que no han de desestimarse solo por cierto recelo a las nuevas tecnologías. La sustitución del antiguo cuaderno escolar por plantillas como las planteadas en este trabajo, se podrian impulsar de la misma forma que se ha ido sustituyendo la pizarra ordinaria por la pizarra digital en los últimos tiempos.

\subsection{Tendencia informática en las aulas}

Hasta hace poco estábamos inmersos en un clima de trabajo total para los maestros con la implantación de la sexta hora, hecho que supuso un gran número de contrataciones. La entrada masiva de maestros no ha implicado una mayor cantidad de trabajadores cualificados, puesto que todavía nos estamos encontrando con una gran cantidad de personal sin unos niveles de informática básicos. Los conocimientos de muchos maestros son bastante discretos, de modo que apenas alcanzan un manejo de las herramientas más básicas, como los programas Word y PowerPoint.

El reciclaje para los maestros de la antigua generación es necesario, pero siempre teniendo en cuenta la dificultad que entraña la formación en cualquier nueva tecnología, incrementada por la edad de quien recibe dicha formación.

Se ha constatado en algunos estudios como el realizado por Canales en 2007 que la tercera parte de profesores no saben informática. Y estamos hablando de secundaria, de personas con formación de licenciatura, mucho más extensa que la antigua diplomatura de Magisterio y que dan clase en un medio donde abundan proyectos como el $1 \times 1$ de Cataluña, consistente en un ordenador por alumno y la utilización de pizarras digitales.

Los cursos de formación obligatoria de reciclaje del profesorado de 30 horas pocas veces tocan aspectos informáticos, y este aspecto debería revisarse, ya que en la actualidad la solución simplemente pasa por derivar la responsabilidad a otros maestros más jóvenes o con mayores conocimientos informáticos para que realicen el trabajo informático de los demás en el centro. Se produce así una acumulación de responsabilidad en vez de compartir conocimientos con el resto del claustro de forma adecuada, sobre todo por el temor a no poder asimilar estos conocimientos.

Quizás, comprobar las posibilidades que la informática ofrece permita que los maestros valoremos más a esta aliada de la educación en el futuro. 


\section{BIBLIOGRAFÍA}

Airasian, P. [2000]: La evaluación en el salón de clases, México: Sep-McGraw-Hill Interamericana Editores.

Alsina, C. [2008]: Vitaminas matemáticas, Barcelona: Ariel.

Álvarez González, M. [1995]: Orientación profesional, Barcelona: Cedecs, 1995.

Álvarez Méndez J. M. [2001]: Evaluar para conocer, examinar para excluir, Madrid: Ediciones Morata, 2001.

Antivi, A. [2005]: La constante macabra o cómo se ha desmotivado a muchos estudiantes, Madrid: El Rompecabezas, 2005.

Canales, R. [2007]: Identificación de factores que contribuyen al desarrollo de actividades de enseñanza y aprendizaje con apoyo de las TIC, que resulten eficientes y eficaces. Análisis de su presencia en tres centros docentes, tesis doctoral dirigida por el doctor Pere Marquès, Universitat Autònoma de Barcelona, España.

Canavos, G. [1992]: Probabilidad y estadística, Madrid: McGraw-Hill.

Casanova, M. [1992]: La evaluación, garantía de calidad para el centro educativo, manual para la evaluación interna de los centros docentes, Zaragoza: Edelvives.

[2004]: Evaluación y calidad de centros educativos, Madrid: La Muralla.
Castillo Arredondo, S. [2003]: Evaluación educativa y promoción escolar, Madrid: 2003.

lafrancesco Villegas, G. [1995]: Proyecto pedagógico para el preescolar: enfoque integral Individuo-ambiente, Colombia: Editorial Libros \& Libros, SA.

Isaacs, D. [1997]: Teoría y práctica de la dirección de Ios centros educativos, Navarra: Eunsa.

Fleitman, J. [1993]: Evaluación integral, México: Editorial McGraw-Hill, 1993.

[2008]: Evaluación integral para implantar modelos de calidad, México: Editorial Pax.

Ley orgánica 5/1980, de 19 de junio, por la que se regula el estatuto de centros escolares (BOE núm. 154, de 27 de junio de 1980, págs. 14.633-14.636).

Ley orgánica 1/1990, de 3 de octubre, de ordenación general del sistema educativo (BOE núm. 238, de 4 de octubre de 1990, págs. 28.927-28.942).

Ley orgánica 10/2002, de 23 de diciembre, de calidad de la educación (BOE núm. 307, de 24 de diciembre de 2002, págs. 45.188-45.220).

Ley orgánica 2/2006, de 3 de mayo, de educación (BOE núm. 106, de 4 de mayo de 2006, págs. 17. 158-17.207).

Real Decreto 696/1995, de 28 de abril, de ordenación de la educación de los alumnos con necesidades educativas especiales (BOE núm. 131, de 2 de junio de 1995, págs. 16.179-16.185). 